\title{
PULL-OUT BEHAVIOUR OF GLASS-FIBRE REINFORCED POLYMER PERFORATED \\ PLATE CONNECTORS EMBEDDED IN CONCRETE. PART II: PREDICTION OF LOAD CARRYING CAPACITY
}

\author{
Rodrigo Lameiras*1, Joaquim A. O. Barros ${ }^{2}$, Isabel B. Valente², José Xavier ${ }^{3,4}$ and Miguel Azenha ${ }^{2}$ \\ ${ }^{1}$ University of Brasília. Department of Civil and Environmental Engineering, Faculty of Technology. Campus \\ Darcy Ribeiro, 70910-900, Brasília, Brazil. Tel: +55 61 31075502; E-mail address: rmlameiras@gmail.com. \\ ${ }^{2}$ ISISE, Universidade do Minho, Campus de Azurém. 4800-058. Guimarães, Portugal. \\ ${ }^{3}$ CITAB, Universidade de Trás-os-Montes e Alto Douro. 5001-801. Vila Real, Portugal. \\ ${ }^{4}$ Optics and Experimental Mechanics Laboratory, INEGI, Campus da FEUP. 4200-465. Porto, Portugal.
}

\begin{abstract}
The authors have recently proposed an innovative connector system that consists on a Glass Fibre Reinforced Polymer (GFRP) perforated plate that is embedded into Steel Fibre Reinforced Self-Compacting Concrete (SFRSCC) layers. The connection is strongly based in the mechanical interlock assured by the dowels originated from the SFRSCC passing through the holes opened on the GFRP plates. In this study, an analytical framework to evaluate the load capacity of the connections when loaded transversally was developed based on experimental pullout tests presented in the companion paper (Part I). For a better understanding of the mechanical behaviour of the connections and to allow to make estimations of the load capacity of connection when it is conditioned by the rupture of the connector itself, pull-out pin-bearing tests with single-hole plates were executed to assess the effect of the type of GFRP on the strain distribution in the vicinity of the holes until the failure, as well as the estimated failure modes and load capacities of the connections.
\end{abstract}

\section{KEYWORDS}

Pull-out; Glass-Fibre Reinforced Polymer (GFRP); PERFOFRP connector; Fibre Reinforced Self-Compacting Concrete (SFRSCC); bearing test.

*- corresponding author. 


\section{INTRODUCTION}

In the recent past, the authors proposed the use of an innovative type of Glass Fibre Reinforced Polymer (GFRP) connector for concrete structural sandwich panels $[1,2]$, hereinafter referred to PERFOFRP. It consists of perforated GFRP plates, as shown in Figure 1Figure 1, that materialize the connection by means of mechanical interlock between the GFRP plate and the concrete dowels originated from the embedment of the connector into the concrete layers. The advantages of the proposed device are inherent to its material nature, of fibre reinforced polymer, since this connector reduces significantly the thermal bridge occurred when steel connectors are used, is not prone to corrosion and is lightweight. The proposed connector is particularly attractive for application in structural sandwich panels that are part of building façades, since an overall improved thermal performance can be achieved with this technology. These connectors have a relatively simple manufacturing process, are easily transported, handled and installed in the panel production process.

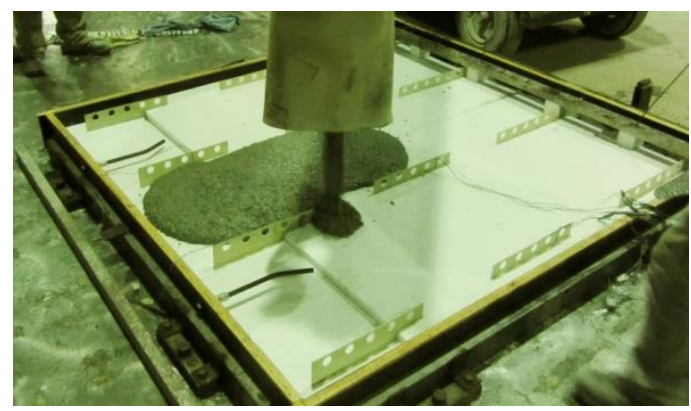

(a)

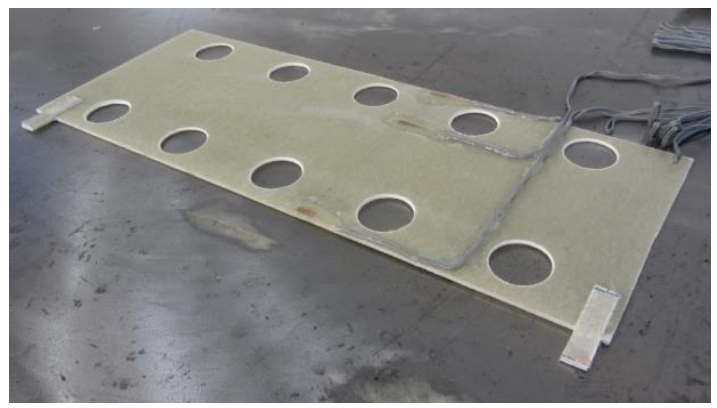

(b)

Figure 1: GFRP connector for concrete structural panels: (a) overall view of connectors during the casting of top concrete layer of a sandwich panel; (b) detail of one PERFOFRP connector.

As observed on the first part of this paper [3], the failure of the connection when subjected to pull-out forces can occur in different modes, depending on the geometry and materials used in the connections. The pull-out experimental program evidenced that the load capacity can be conditioned by failures in the concrete or even in the GFRP connector itself, in the vicinity of the holes. Nonetheless, although the connector failure was evidenced in the post testing inspection, due to the fact that the connector is embedded in the concrete, the conditions at which the rupture actually occurs and the underlying mechanisms could not yet be fully understood nor explained. Despite the relatively high tensile strength of the GFRP in the context of the materials used in concrete sandwich panels, failure through the GFRP can irremediably compromise the structural performance of this type of panels, since the these materials generally present a brittle behaviour, thus leading to an undesirable sudden rupture of the panel.

In the technology of the perforated composites for mechanically fastened connections this issue could be solved by establishing minimum distances from the holes to the border of the laminate to be followed in the design process. 
However, in the case of proposed PERFOFRP connections, the diameter of holes and the distance from border are limited by the application given to the connector. In fact, when compared with the geometries of the usual perforated plates for mechanically fastened connections, the diameter of the hole used in the PERFOFRP is larger (usually ranges between 3 and $10 \mathrm{~mm}$ for fastened connections) and the distance between the hole and the border is shorter $[4,5]$. The diameter of holes should permit the aggregates and fibres of concrete to pass through the holes and promote the expected mechanical interlocking between the concrete and the connector.

For conventionally reinforced concrete, this value could be equal to the clear distance between individual parallel bars recommended by EN 1992-1-1 [6], that is given by the maximum size of aggregate plus $5 \mathrm{~mm}$ (i.e.: $12 \mathrm{~mm}+$ $5 \mathrm{~mm}=17 \mathrm{~mm}$ for the materials used in this research). Nonetheless, the steel fibres used as reinforcement of concrete has length equal to $35 \mathrm{~mm}$. To avoid fibre congestion, the diameter of holes was set equal to $30 \mathrm{~mm}$. The distance of hole from the border is limited by the relatively small thickness of concrete layer, that, based on the recommendations made in a first study (Lameiras et al., 2013a), was set at only $60 \mathrm{~mm}$. Considering a minimum cover to the GFRP of $15 \mathrm{~mm}$, value also limited by the maximum diameter of aggregate used in the concrete, the length that remains for the distance from the centre of hole to the laminate border is only $22.5 \mathrm{~mm}$, meaning that the distance from the edge of hole to the laminate border is only $7.5 \mathrm{~mm}$. On the other hand, even with all the aforementioned constraints, in a preliminary investigation $[1,2]$, the authors confirmed that the load capacity possible to be attained with the proposed PERFOFRP connection was enough to be used as connector for sandwich wall panels, enabling to take the advantages related to the use of this type of connector.

Although the bearing behaviour of GFRP laminates is a subject well-researched and reported in the literature [4, 5, 7-10], the authors considered that it was necessary to perform bearing tests that were representative of the geometry of proposed connections for a better understanding of the mechanical behaviour of the this particular type of connector. Thus, an experimental program was also undertaken in the scope of the present research, as to determine the failure mechanisms and the strain field around holes of this type of GRP connectors. More specifically, tensile tests were carried out on specimens formed by a multi-directional GFRP plate including a hole (herein designated as single-hole plate), where the hole was supported with a metallic pin to reproduce, as much as possible and in a feasible way, the anchorage conditions expected for the GFRP connector embedded in the sandwich panel concrete layers. The tests were performed for a range of laminate configurations and different positions of the hole relatively to the free-stress contour of the GFRP plate. Furthermore, the strain field in the vicinity of hole was assessed by using a full-field measurement technique, and also registering local measurements with electrical strain gauges.

Finally, based on the experimental evidence of the pull-out tests presented in the first part of this companion paper [3] and on the results from the bearing tests here presented, an analytical framework is proposed for prediction of the 
load carrying capacity, when subjected to pull-out loads, of connections between PERFOFRP connectors and plain or steel fibre reinforced concrete. This analytical framework emerged from the interest on a better understanding of the functionality and anchorage mechanics of the proposed connectors, which will enable the optimization of the connectors' geometry for different materials and applications (e.g.; optimization of distances between holes and from the stress-free edge).

\section{EXPERIMENTAL STUDY ON THE PIN-BEARING BEHAVIOUR OF PERFOFRP CONNECTORS}

\subsection{Expected Failure Modes}

Despite the specificities of the PERFOFRP connectors, some similarities with the plates used in bolted joints can be still be found. For instance, apart from failure of the concrete pin in either shear or compression, it can be considered that the potential failure modes might be expected to be similar. Specific literature on strength of perforated plates for mechanically fastened joints $[11,12]$ generally considers that the failure of the connection occurs in one of the four potential modes illustrated in Figure 2Figure 2: net-tension, shear-out (or tear-out), bearing, and cleavage.

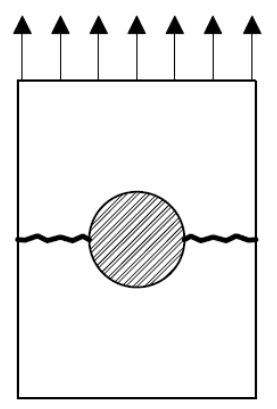

(a)

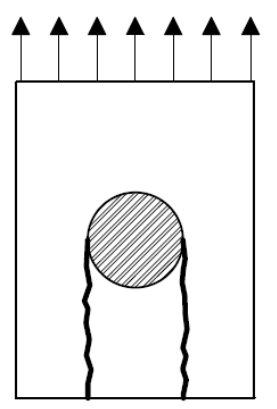

(b)

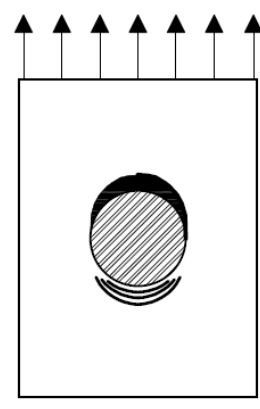

(c)

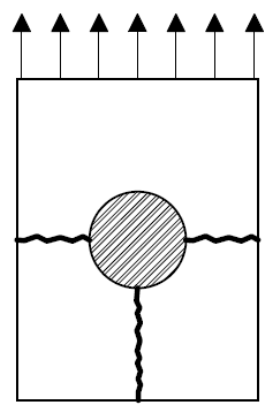

(d)

Figure 2: Common failure modes described in the literature: (a) net-tension; (b) shear-out; (c) bearing; (d) cleavage.

Net-tension is a lateral failure at the minimum cross-section perpendicular to the loading direction (Figure 2Figure Za). The stress that is introduced in net section is schematically represented in the Figure 3Figure $3 \mathrm{a}$ and can be determined from Eq. (1(1).

$$
\sigma_{n t}=\frac{Q}{\left(W-D_{h}\right) \cdot t_{p}}
$$

where $Q$ is the applied load, $W$ is the width of the specimen, $D_{h}$ is the diameter of the hole, and $t_{p}$ is the thickness of the laminate. This failure mechanism takes place when $\sigma_{n t}$ reaches the direct tensile strength of the composite in the load direction. 


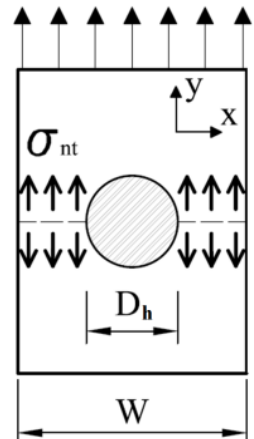

(a)

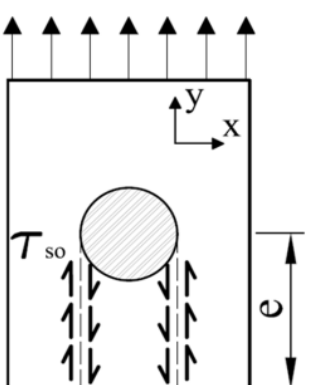

(b)

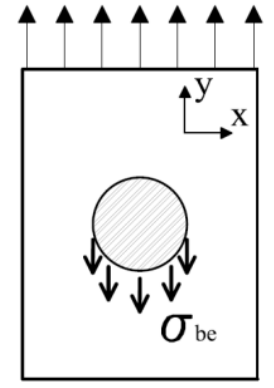

(c)

Figure 3: Schematic representation of the stresses computed for: (a) net-tension; (b) shear-out; (c) bearing.

Shear-out or tear-out is the rupture of the part below the hole due to the occurrence of two lateral failure surfaces with origin in the lateral extremities of the hole (Figure 2Figure 2b). The shear stress can be computed with Equation $\underline{(2(2)})$

$$
\tau_{s o}=\frac{Q}{2 \cdot e \cdot t_{p}}
$$

where $e$ is the distance from the bottom edge to the lateral extremity of the hole (see Figure 3 Figure $3 \mathrm{~b}$ ). If the shear stress $\tau_{s o}$ reaches the shear strength of material, shear-out or tear-out failure occur.

Bearing failure involves a local compression in the composite immediately beneath the loading pin (see Figure 2Figure 2c). Despite the variation of compressive stress along the perimeter contact between the pin and the hole, it is usually assumed that the applied load acts uniformly on the projection of the perimeter of the bottom semicircumference of the hole on a surface perpendicular to the load direction (see Figure 3Figure 3c). The bearing stress is thus obtained with Equation $\underline{3}(3)$.

$$
\sigma_{b e}=\frac{Q}{D_{h} \cdot t_{p}}
$$

Some researchers [12] have pointed out that due to the lack of plasticity of GFRP, a ductile behaviour for the connection is only attained when a bearing failure is observed. This happens because during bearing failure mode, the joint is able to support significant load after first failure.

The cleavage is considered a mixed failure mode between the shear out and net tension that occurs due to relatively small edge distance $[13,14]$. 


\subsection{Factors Affecting Failure}

Several researchers $[4,8,10,12,15-17]$ indicate that the type of failure mode that occurs in a fastened joint is mainly dependent on the width-to-diameter $\left(W / D_{h}\right)$ and edge-to-diameter $\left(e / D_{h}\right)$ ratios. They also indicate that while a low $W / D_{h}$ favours the occurrence of net-tension, a low $e / D_{h}$ induces shear-out or cleavage failure modes. The type of composite material can also affect the overall behaviour of the connection. In an experimental investigation on bearing behaviour of an E-glass/vinyl-ester epoxy composite, Wu and Hahn [17] verified that a quasi-isotropic composite has higher ultimate bearing strength than chopped strand materials composite (CSM). Nonetheless, Smith and Pascoe [18] found that, for GFRP, the effect of different stacking sequence did not influence significantly the bearing strength.

The effect of the lateral restraint on the material bearing strength for this type of test was evaluated in several studies $[12,15,16]$ by comparing bolted to pinned bearing tests and also by evaluating the effect of the clamping torque on the bearing behaviour. These studies showed that lateral restraint always improved the bearing capacity of glassfibre and glass-fibre/aluminium laminates. This occurs when pure bearing failures mode are expected. As presented in section 2.1, this failure mode is related to the compressive forces in the composite immediately beneath the pin. Furthermore, delamination of laminate has also a tendency to occur, resulting in a mixture of compressive and delamination failure at the bolt hole. Thus, the applied clamping force prevents the expected delamination, which increases the failure load.

In the specific case of the connectors proposed by the authors, the concrete tends to promote some lateral confinement of the laminate. Nonetheless, in the regions where the concrete is mainly under tensile stresses or if there is some transverse flexure, this favourable confinement effect can be rendered irrelevant.

Previous studies [19-22] have shown that, when the composite plate is loaded by multiple pins, the bearing strength of the composite is dependent upon the ratio between the distance between the holes and their diameter. This aspect seems to be very significant on the proposed laminate connector, since it is comprised of several aligned holes (see Figure 1Figure 1).

\subsection{Experimental Program}

The experimental program, carried out at the Laboratory of the Structural Division of the University of Minho, included a total of 29 pin-bearing tests, with at least 3 identical tests of each variant. Emphasis was given on investigating the effect on failure modes and strength of single-hole plate of using: (i) different multi-directional GFRP; (ii) diverse distances between the hole and the free-stress edges of the specimen. 
In addition to the CSM and MU4 laminates employed in the tests with the GFRP vs. concrete connections under pull-out loads [3], in the pin bearing tests, two other materials were employed: BIA and MU2. Detailed description of laminates and the material properties of the four laminates employed in the pin-bearing tests are given in the first part of this companion paper [3].

\subsection{Test Specimens}

For each one of the four types of materials tested, a large rectangular flat plate was prepared with about $1500 \times 1000 \mathrm{~mm}^{2}$. The specimens are cut out from the plates by a diamond saw. The longer dimension of the specimens (see Figure 4Figure 4 ) coincided with the $0^{\circ}$ or $90^{\circ}$ orientation axis of the material according to the referential shown in Figure 4Figure 4. The pin holes were then drilled by a $30 \mathrm{~mm}$ diamond grit hole saw.

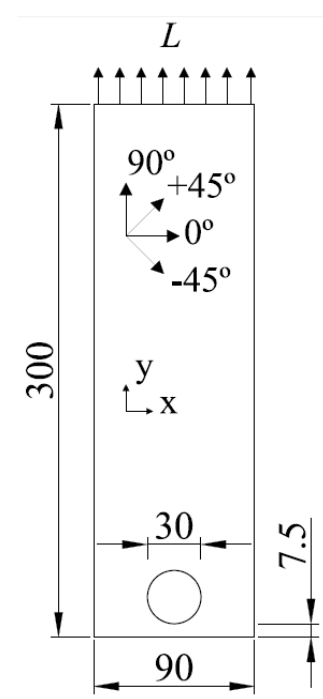

(a)

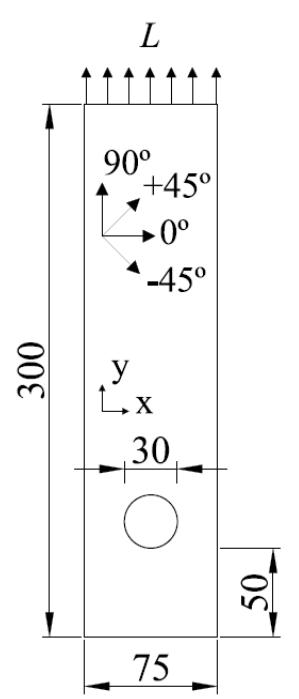

(b)

Figure 4: Type of specimens: (a) BEL; (b) LAT (dimensions in millimeters).

Two types of tests, using different specimen geometries, were carried out for the determination of bearing strength. The specimens had different $\left(W / D_{h}\right)$ and $\left(e / D_{h}\right)$ ratios. These ratios intended to be representative of the two failure modes in the GFRP connectors observed on the pull-out tests presented in the first part of this companion paper [3]. The BEL specimen type (Figure 4Figure 4a) was designed to induce the cleavage failure mode in the region of the laminate immediately below the hole, while the LAT specimen type (Figure 4Figure 4b) was specially designed to cause a net-tension failure mode. The chosen values for the $W / D_{h}$ and $e / D_{h}$ ratios are representative of the connectors investigated in the first part of this companion paper [3], where a distance of $2.5 \cdot D_{h}$ between centre of holes was adopted. To simplify, in this paper the effect of multiple holes was not considered, and thus, the tested specimens with only comprise a single hole. The distances between the holes adopted in the connectors presented in Lameiras et al. [3] were based on recommendations resulted from studies with similar steel connectors [23, 24], 
where the ratio between distance between holes and the diameter of hole is mainly conditioned by concrete properties.

\subsection{Test Setup}

The test set-up used in this investigation was designed to be as representative as possible of the conditions imposed in pull-out tests performed with GFRP connectors in the first part of this paper [3].

Despite disregarding the confinement effect of the concrete surrounding the connector, the pin-bearing test configuration was the selected one for the present tests since it provides conservative results in terms of the strength capacity and ductility when compared to the expected behaviour of the connector when embedded in the sandwich panel.

An aluminium pin with $30 \mathrm{~mm}$ diameter was tightly attached to the circular hole of specimen in the bottom extremity of the composite, and the gripping was made by a manual mechanical action wedge grip located on the top extremity of specimen (see Figure 5Figure $5 \mathrm{a}$ and Figure 5Figure $5 \mathrm{~b}$ ). To increase the specimen-grip friction and to avoid any specimen's slippage, rough inner surface grips were used. An anchorage length of $90 \mathrm{~mm}$ for the GFRP laminate was always adopted to assure proper gripping conditions for all types of laminates tested. Steel tabs with $1 \mathrm{~mm}$ thickness, $90 \mathrm{~mm}$ height and with the same width of the specimens were glued on their both sides in the gripping region. This was done as an attempt to assure, as much as possible, an uniform distribution of shear stresses in the zone where the load was transferred from the grip to the specimen, contributing to prevent a premature rupture of the specimen.

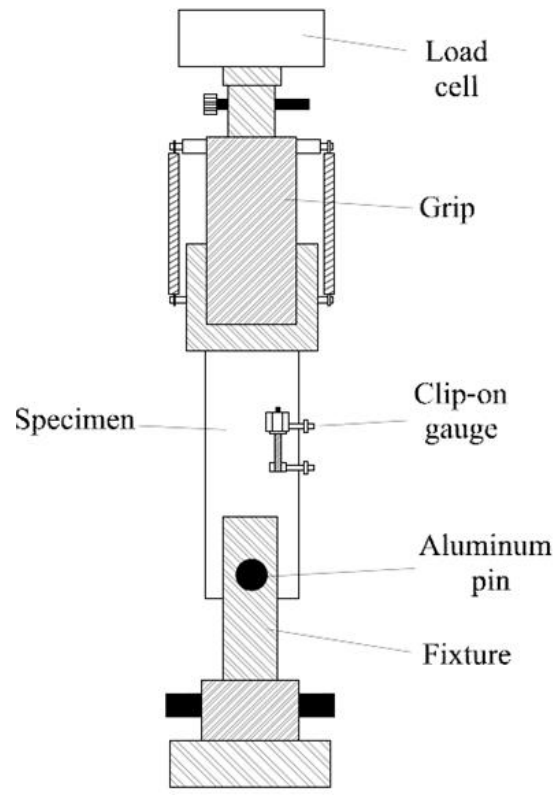

(a)

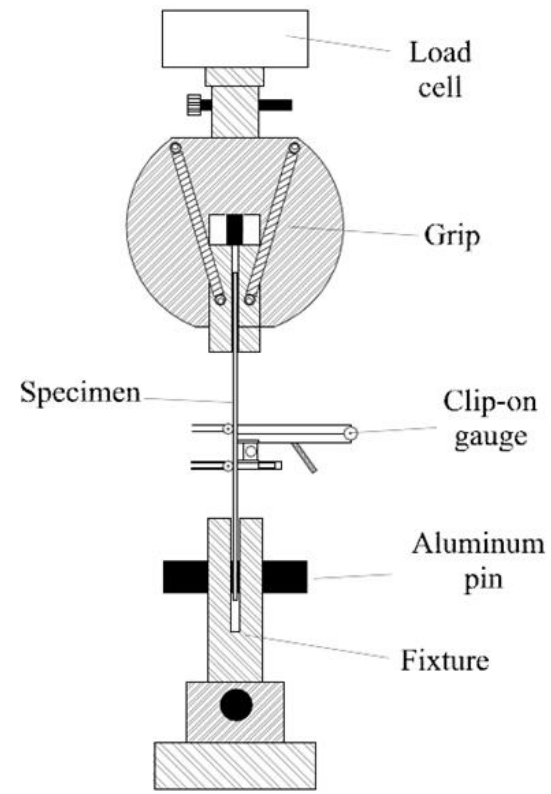

(b) 


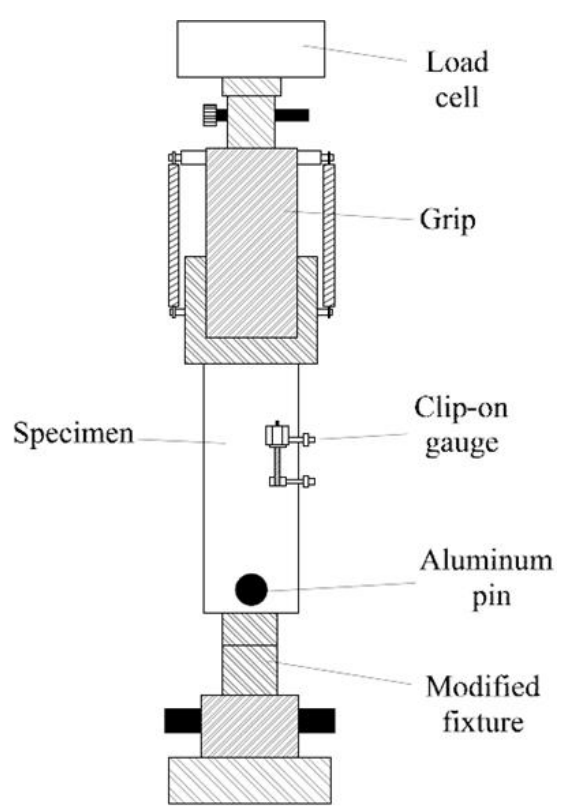

(c)

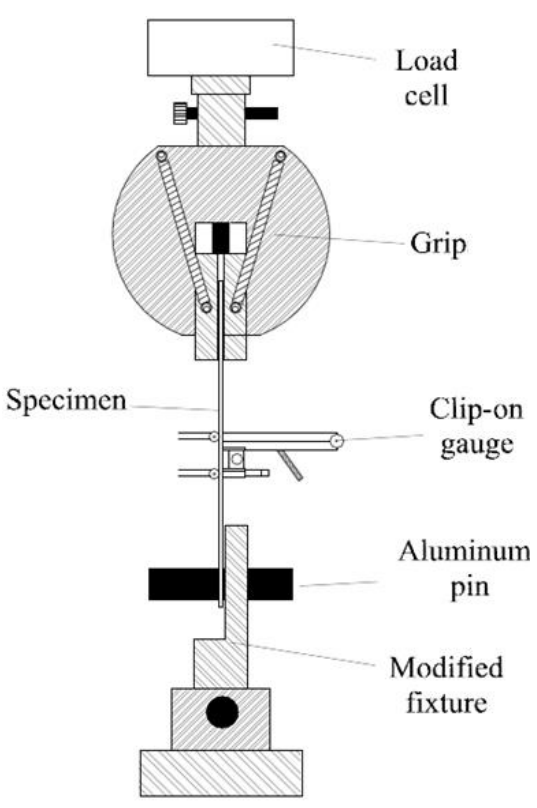

(d)

Figure 5: Schematic representation of test-setups adopted for the pin-bearing tests: (a) original test setup (SIM): front view; (b) SIM: lateral view; (c) modified test setup (CAN): front view; (d) CAN: lateral view.

More representative conditions of the reality would be obtained if a SFRSCC pin was used in the tests. However, besides some complexity associated with the production of a concrete pin, it would be possible to experience earlier failures in these pins, for a load level lower than the ones corresponding to the failure modes of the GFRP. Thereby, avoiding the occurrence of these types of failures modes was critical for the study of the intended mechanisms of rupture. Hence, aluminium was the selected material, in replacement of a commonly employed steel pin, because its modulus of elasticity is more approximated to that of concrete, while still maintaining tensile/shear strength levels that are high enough to avoid the failure within the pin.

A double-lap single-pin joint was considered for the experimental model. The aluminium pin passed through a specially manufactured steel fork support that was attached to the base of the test machine crosshead, as represented in Figure 5Figure 5a and Figure 5Figure 5b. A variation of this test setup was also used in five additional tested specimens in order to have full visual access to one surface of the specimen during the tests, allowing to record the damage initiation and propagation for the different failure modes by using an optical full-field measurement technique. This variation of the test setup is illustrated in Figure 5Figure $5 \mathrm{c}$ and Figure 5Figure $5 \mathrm{~d}$, and was obtained by removing one side of the steel fork fixture where the aluminium pin was attached. By removing this part from the original device of the test setup, the aluminium pin became a cantilevered element (see Figure 5Figure 5). Hereinafter the original and modified test setups were designated by SIM (simply supported) and CAN (cantilevered), respectively. 
All the tests were performed in tension on a MicroTest (SCM4000) universal test machine (Figure 6Figure 6a), by imposing a displacement control, at constant cross-head speed of $2 \mathrm{~mm} / \mathrm{min}$.

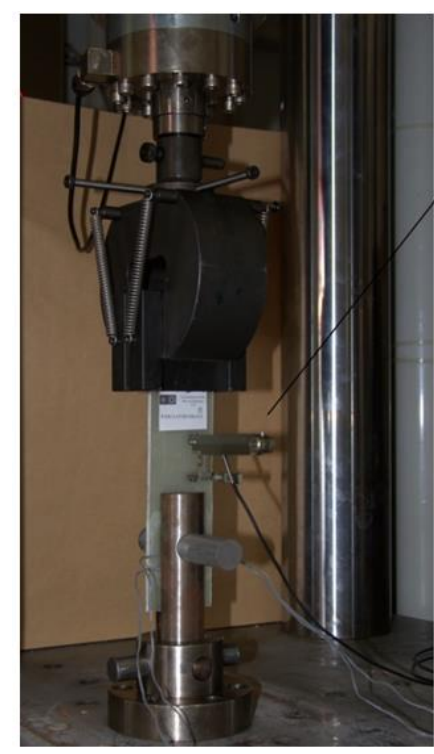

(a)

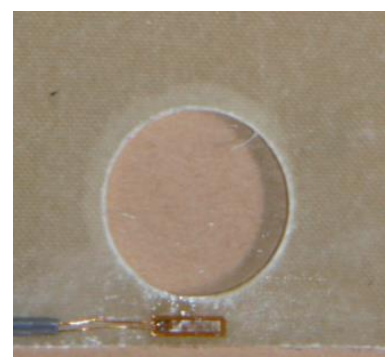

(c)

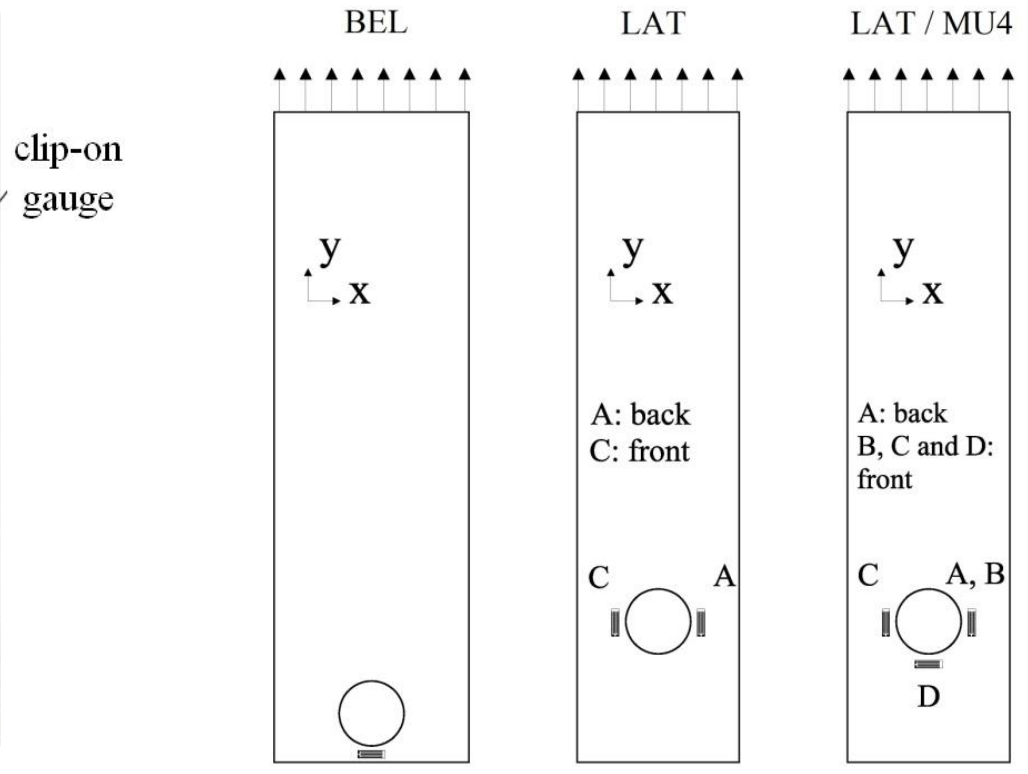

(b) back view:

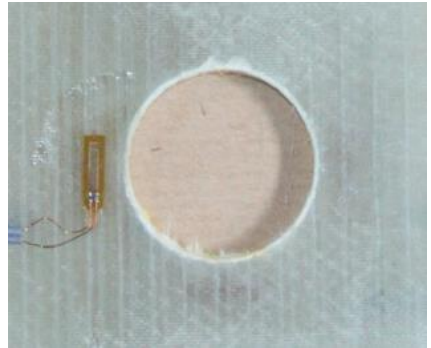

front view:

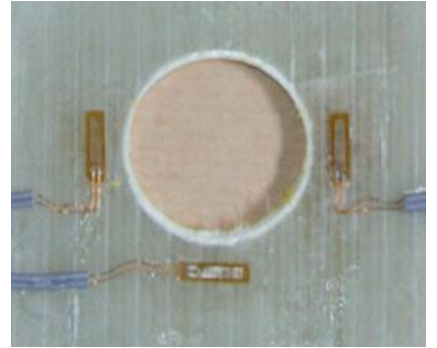

(d)

Figure 6: Instrumentation adopted: (a) clip-on gauge in the middle section of specimen; (b) schematic representation of three configurations adopted to measure the deformation in the proximity of hole; (c) detail of the ESG glued immediately below the hole of BEL specimen; (c) detail of ESG glued next to the hole of LAT / MU4 specimen.

\subsection{Instrumentation}

For each test, load versus displacement plots were obtained, where the displacement is obtained from the cross-head movement. The load was measured by a $200 \mathrm{kN}$ load cell at a rate of $2 \mathrm{~Hz}$. The load cell was connected in series to the cross-head and to the loading clamp device (Figure 5Figure 5).

The nominal axial strain was measured in all tests using a clip-on gauge with a reference length of $50 \mathrm{~mm}$, attached to the middle part of the specimens (see Figure 5Figure 5 and Figure 6Figure 6a). The strain distribution in the 
vicinity of the hole was experimentally determined by using several electrical strain gauges (ESG). As represented in Figure 6Figure 6b, at least one specimen of each test configuration and also of each GFRP material was instrumented with ESG. One ESG was placed immediately below the hole in the BEL specimens and one pair of ESG was glued at the left and right sides of the hole in the LAT specimens. These positions were chosen because they are the most susceptible to the occurrence of the highest strain gradients. The two ESG used in the LAT specimens were placed on the front and rear sides of the laminate in order to evaluate the symmetry of test, identifying the possible occurrence of bending due to some misalignment. For a better understanding of the strains development in the proximity of holes, one LAT/MU4 specimen (i.e.; LAT test configuration with a specimen comprising MU4 material) comprised additional strain measurement by using four electrical strain gauges arranged as illustrated in Figure 6Figure 6d. All the ESG were attached to the laminate at a distance of approximately $3 \mathrm{~mm}$ from the hole edge (distance measured between the middle section of ESG and the hole edge).

The strain field around the hole connection was also evaluated by means of Digital Image Correlation (DIC). This white-light optical technique provides the full-field displacement of a target surface by correlating images recorded at different instants. The material surface must have a textured pattern, defining locally an unique feature-based region. At the scale of observation, a speckle pattern is created using a white-to-black spray painting technique to ensure suitable contrast and granular size. The quality of this pattern is relevant to ensure a good balance between spatial resolution and accuracy, which is particularly crucial in this application. In this work, the ARAMIS system by GOM was used [25-27]. The optical system was equipped with an 8-bit Baumer Optronic FWX20 digital camera coupled with a Zoom-Nikkor 28-105mm f/3.5-4.5D IF. The aperture, the lighting intensity and the shutter time were set to enhance contrast of the speckle image. Considering the characteristic dimensions of the region of interest, the optical magnification and the quality of the speckled pattern, a subset of $15 \times 15$ pixel $^{2}\left(1.08 \times 1.08 \mathrm{~mm}^{2}\right)$, with an overlapping of 2 pixels for enhancing the strain spatial resolution, was chosen. The strain fields were determined by numerical differentiation of the displacement fields by least-square regression over a base length of $5 \times 5$ subsets ${ }^{2}$ $\left(5.4 \times 5.4 \mathrm{~mm}^{2}\right)$. From rigid-body translation tests $[26,28]$, an accuracy of 0.01-0.02 pixel $(0.72-1.44 \mu \mathrm{m})$ and $0.012-$ $0.035 \%$ was obtained for the DIC measurements of displacement and strain, respectively.

\subsection{Failure Modes}

In general, the BEL specimens presented a cleavage failure mode as the sequence exemplified in Figure 7Figure 7a. All BEL specimens exhibited similar behaviour, with initiation of failure at the zone of the minimum cross section area, immediately below the hole, followed by the appearance of two inclined failure lines due to the formation of two cantilevers in the second stage of failure propagation (see photos of BEL specimens after having been tested in Figure 8Figure 8). The failure mechanism was almost the same in all the BEL samples, differing only on the 
ductility of the responses. Still within BEL specimens, for the CSM laminates, the second failure lines occurred more abruptly than in the specimens comprising other types of laminates, as evidenced in Figure 10Figure 10. This may be justified by the existence of a high content of fibres on the $\pm 45^{\circ}$ directions in the other three laminates studied here. In fact, the behaviour of the $\pm 45^{\circ}$ laminates under direct tensile tests along the $0^{\circ} / 90^{\circ}$ directions was always more ductile [29]. This effect was probably more pronounced in the bearing tests due to the higher anchorage length of the fibres arranged on the $\pm 45^{\circ}$ directions.

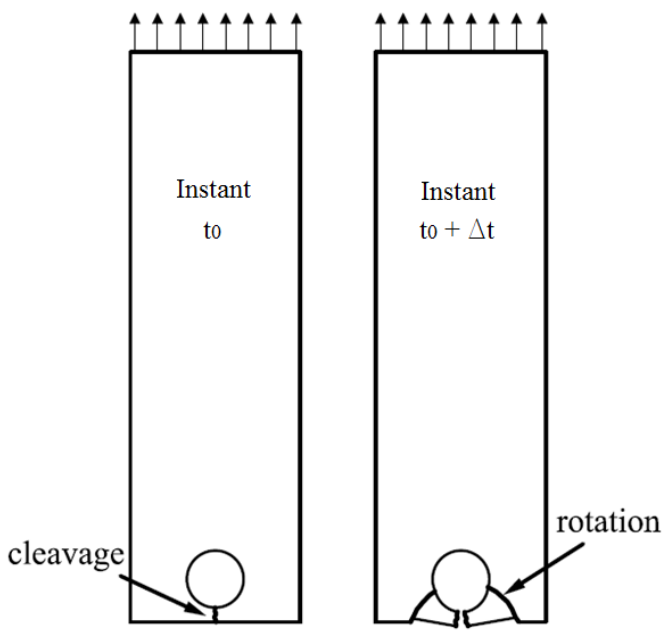

(a)

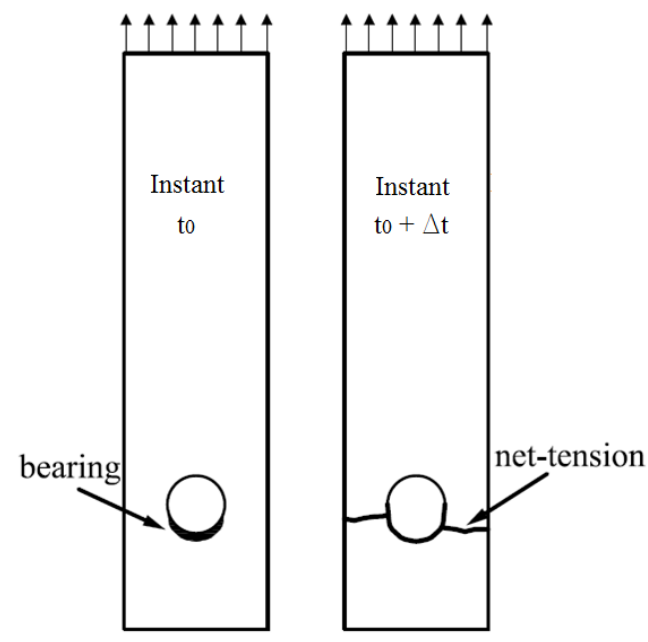

(b)

Figure 7: Typical mixed failure sequence for: (a) BEL specimens; (b) LAT specimens.

On the other hand, bearing and net-tension were the failure modes observed in the case of the LAT specimens. Most specimens showed a mixed bearing and net-tension failure mode as schematized in Figure 7Figure $7 \mathrm{~b}$. From the observations made during tests it was verified that the beginning of failure was characterized by a bearing damage followed by net-tension failure of the laminate. This was the failure mode found for all specimens comprising BIA and MU4 laminates (see tested specimens in Figure 9Figure 9). For these specimens the failure occurred in a relatively ductile fashion. In the specimens with $\pm 45^{\circ}$ plies, a whitening of a limited region was observed prior the net-tension rupture (see Figure 9Figure 9). This whitish region was limited by lines that start in the hole edge and finish in the free lateral edges, at an angle approximately equal to $\pm 45^{\circ}$ with the $x$ axis. It was verified that this pattern was associated to the occurrence of a progressive delamination/damage due to the mobilization of inclined fibres. When the net-tension failure took place, it happened in a sudden way, generally with the propagation of a horizontal crack from the hole edge to the lateral edges of specimen.

The difference between the failure modes of BEL and LAT specimens was attributed to the larger $e / D_{h}(0.75$ and 2.17, for BEL and LAT specimens, respectively) and smaller $W / D_{h}(3.00$ and 2.50 , for BEL and LAT specimens, respectively) ratios of LAT specimens. 


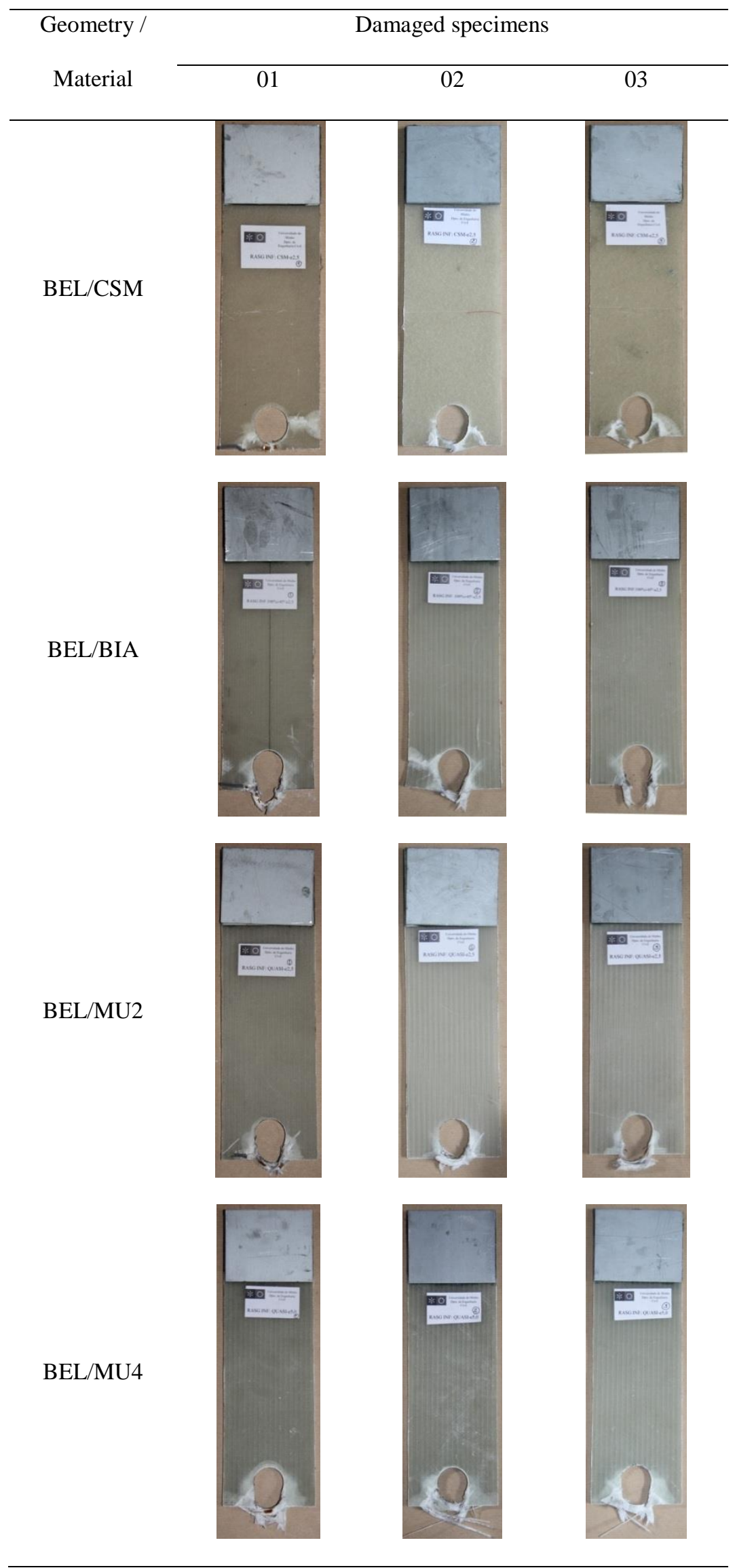

Figure 8: Final appearance of BEL specimens. 


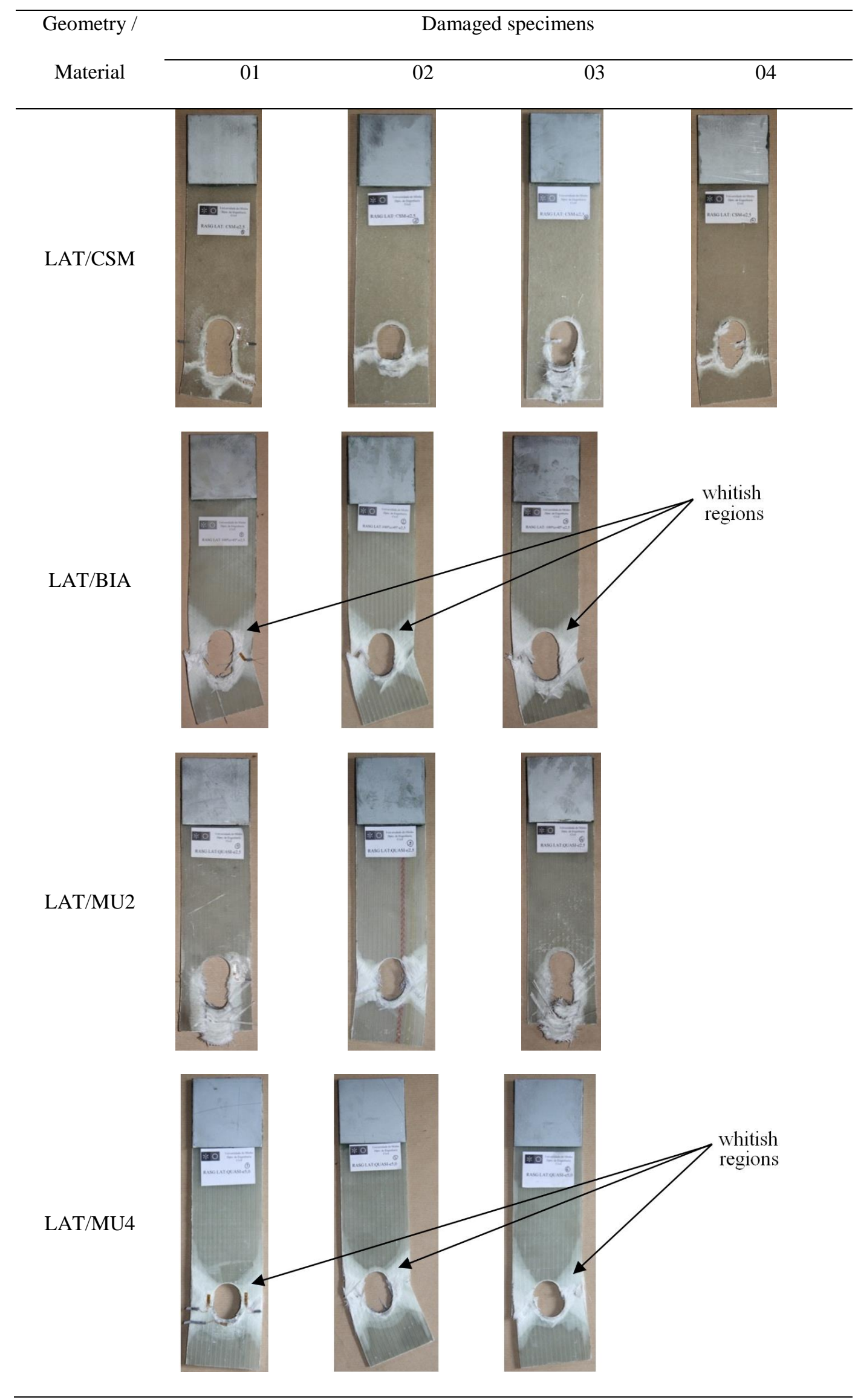

Figure 9: Final appearance of LAT specimens. 
In the case of the four specimens tested according to the CAN test setup, a pronounced out-of-plane displacement was observed in all the specimens tested. Both CAN-BEL specimens present failure by cleavage, while both CANLAT specimens failed by bearing.

\subsection{Bearing Behaviour and Strength}

The general bearing behaviour of laminates was obtained from the load versus displacement relationship. This relationship for BEL and LAT specimens is presented in Figure 10 Figure 10 and Figure 11Figure 11, respectively.

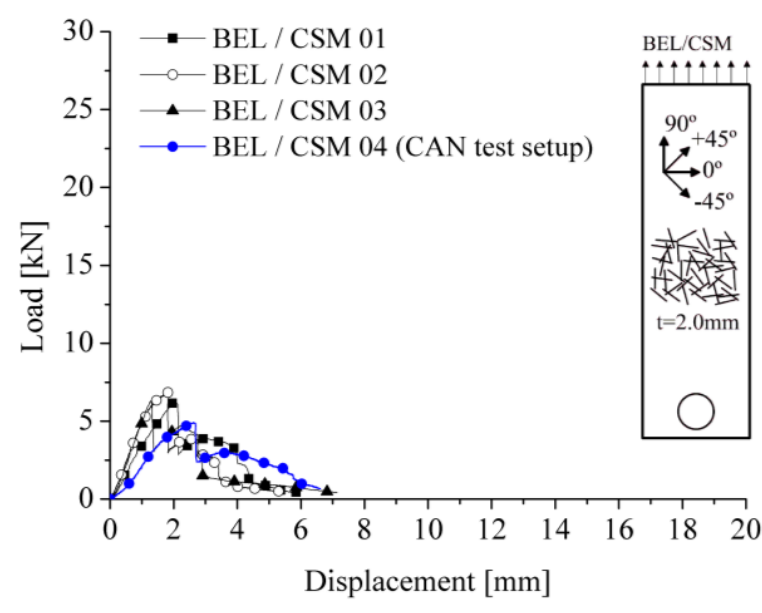

(a)

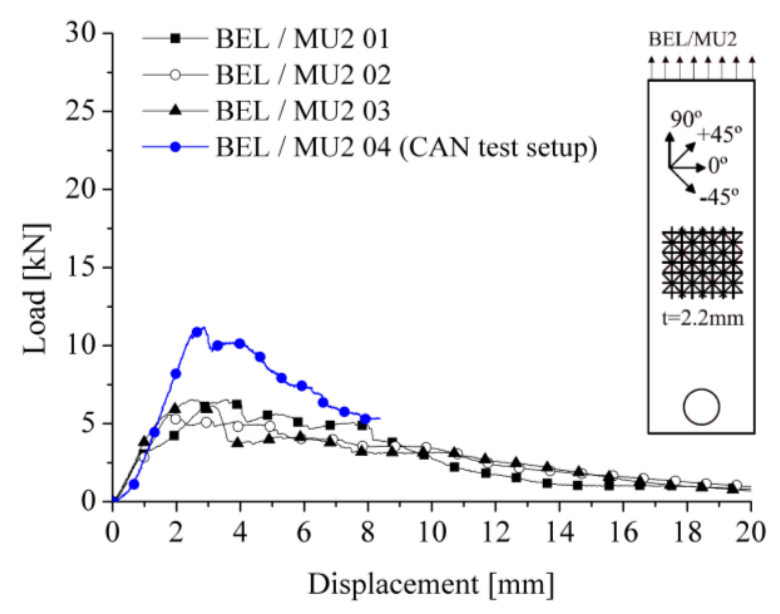

(c)

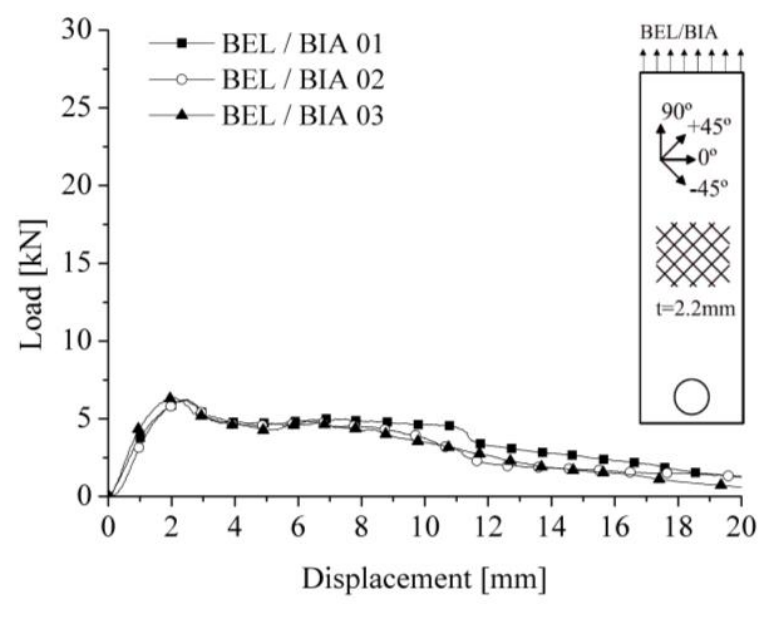

(b)

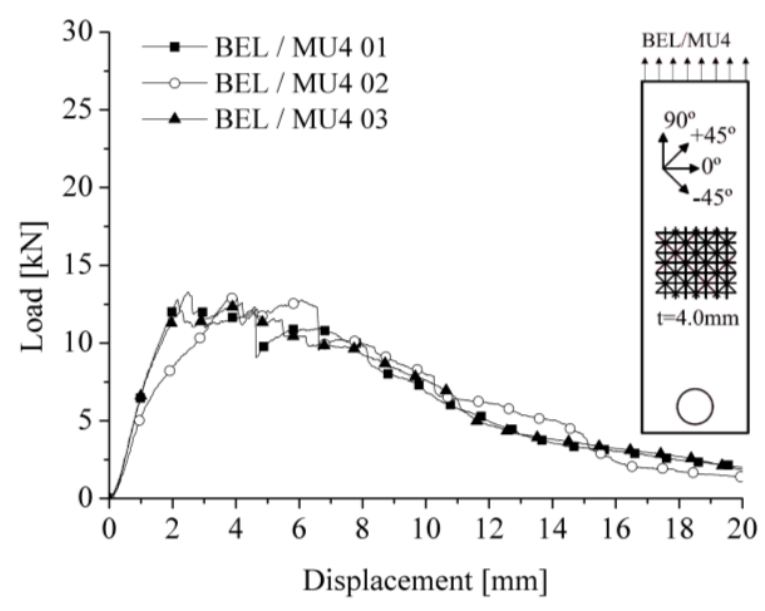

(d)

Figure 10: Load versus displacement curves for the BEL specimens: (a) CSM; (b) BIA; (c) MU2; (d) MU4.

It was noticed that changing the test setup from a balanced solution (SIM) to a cantilevered fixture (CAN) led to different results. In general, different failure modes were obtained with CAN: the initial slope of the force versus displacement curves was smaller than the slope obtained for specimens tested under the SIM test setup, and the ultimate loads were significantly different from the ones obtained when the specimens are tested using the SIM configuration, but without a clear tendency. This particular behaviour obtained for the specimens tested under the CAN test setup possibly have been induced by the out-of-plane displacements observed during the tests when this 
configuration was used. Since in the real connection, within the sandwich panel, the laminate is surrounded by concrete that avoids the out-of-plane movements, the authors believe that the results obtained in the CAN configuration were less representative of the laminate working conditions in the sandwich panel than the results obtained in the SIM test setup. For this reason, the results obtained with the CAN test setup were disregarded in the analyses in terms of failure mode and ultimate load. The results from DIC technique, applied exclusively to the specimens tested with CAN setup, were then only used to obtain information on the strain concentrations in the vicinity of holes.
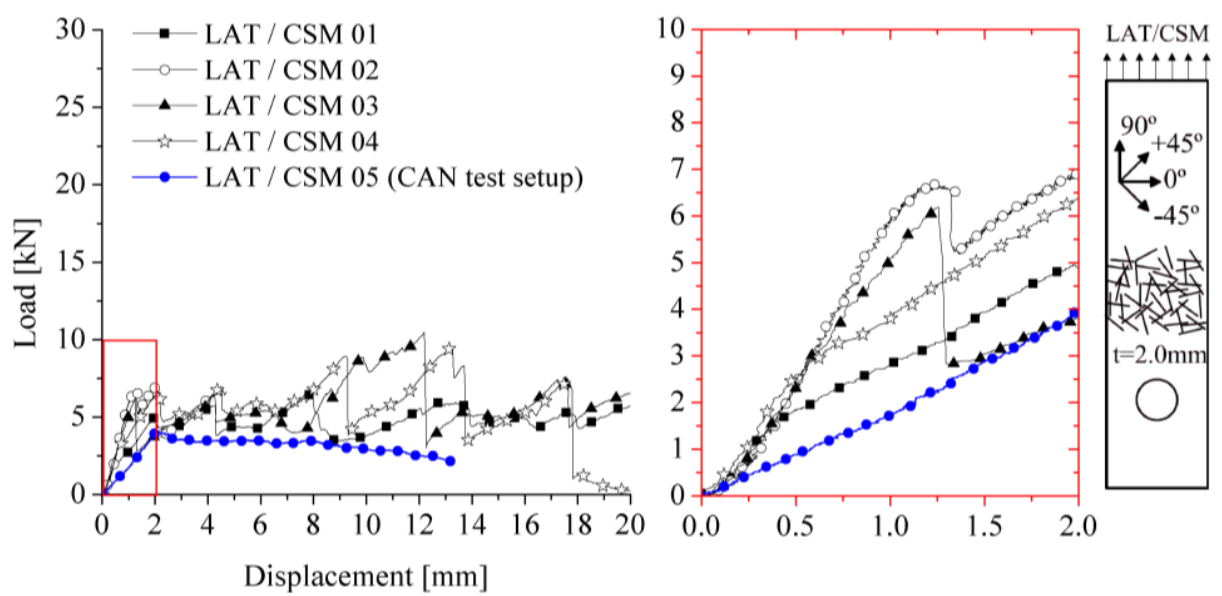

(a)
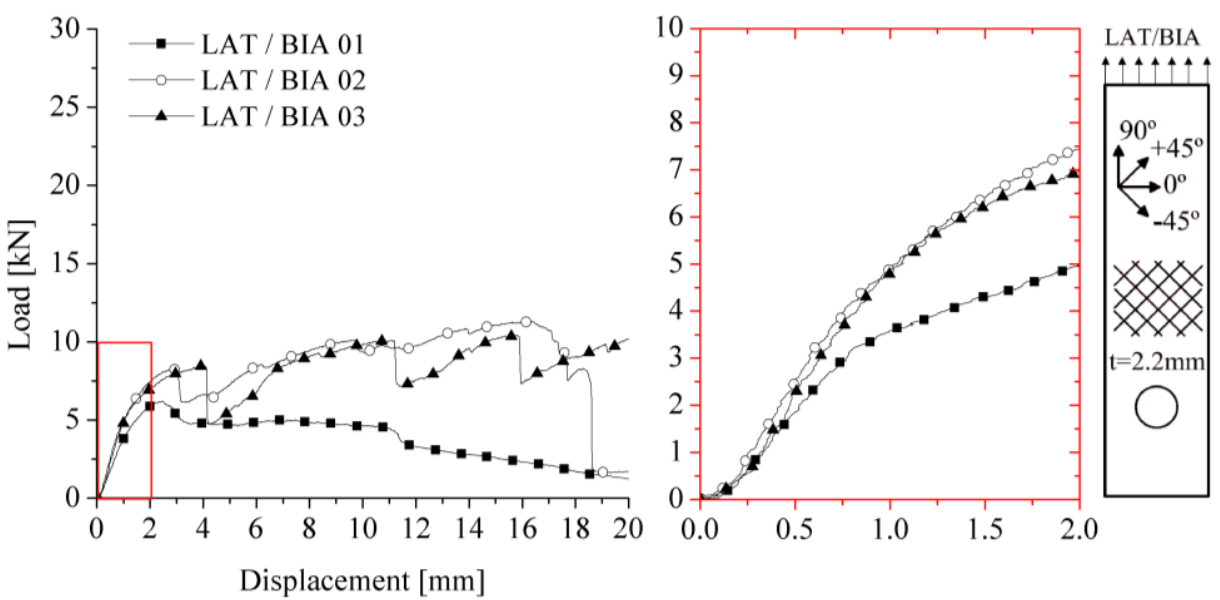

(b) 

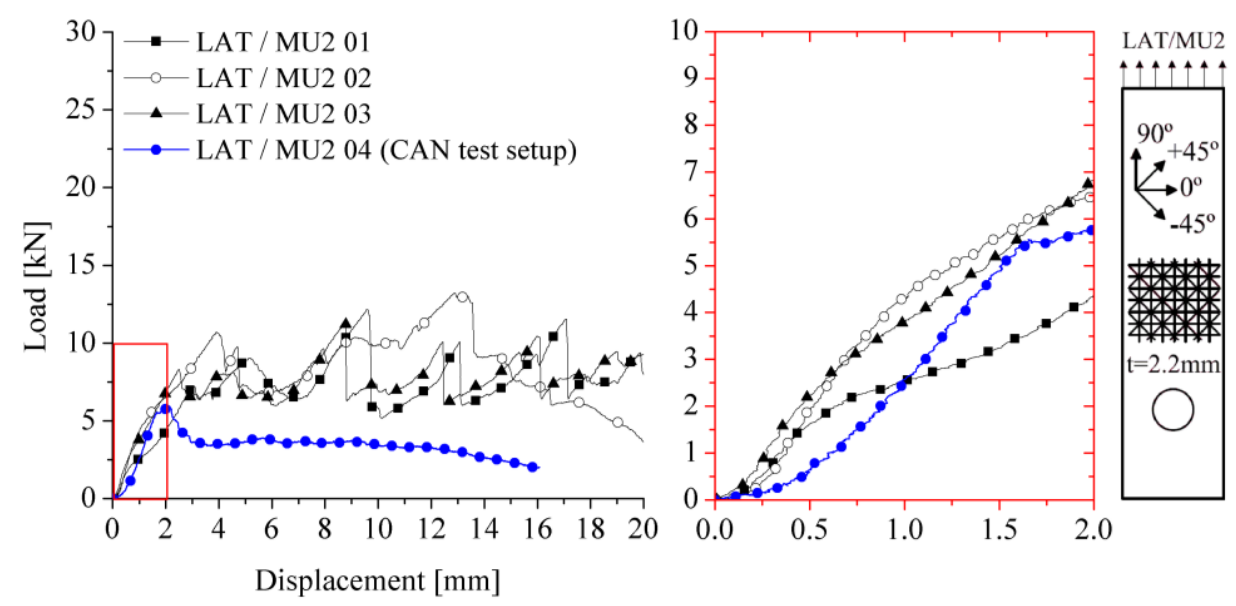

(c)

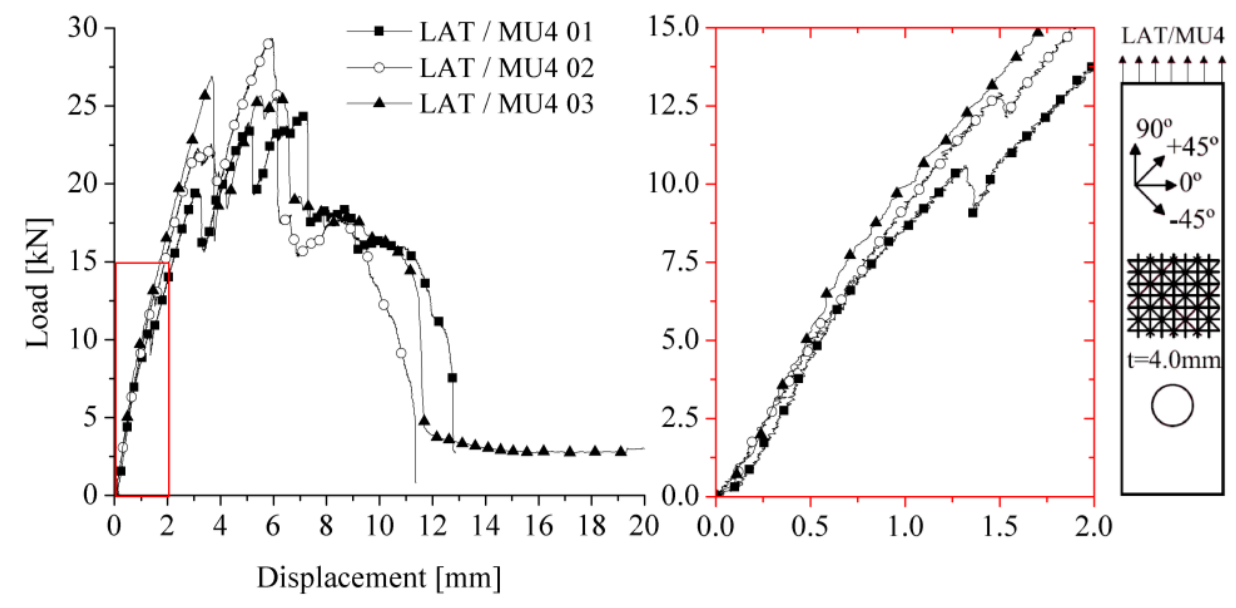

(d)

Figure 11: Load versus displacement curves for the LAT specimens: (a) CSM; (b) BIA; (c) MU2; (d) MU4.

Figure 10Figure 10 and Figure 11Figure 11 show that a similar load versus displacement response was obtained in all specimens of same geometry and material tested in SIM conditions, which is an indication of the reliability of this test setup.

In general, the load versus displacement curves showed a linear response of the specimens, followed by a nonlinear behaviour due to damage in the laminate zones of higher strain gradients adjacent to the hole. This nonlinear branch was longer and more pronounced in the LAT specimens, where the progressive damage due to bearing was more evident. Apart the BEL/CSM and LAT/MU4 specimens, above the deformation corresponding to maximum load the specimens continue to sustain significant part of the peak load up to relatively large axial deformation. In the postpeak load stage of BEL/CSM and LAT/MU4 specimens, the load carrying capacity decreased pronouncedly (see Figure 10Figure 10a and Figure 11Figure 11d). For the LAT specimens a more clear load plateau was noticed, followed by a series of small loading and unloading cycles. Based on observations during tests, this behaviour was associated to visible successive damages related to bearing failure mode. The final failure of specimens occurred 
more abruptly when a net-tension failure took place (e.g.; compare the responses of LAT/MU4 specimens, which failed by net-tension after a short branch of progressive damage associated to bearing mode, with the responses of the other LAT specimens). This observed behaviour seems consistent with the results published by other authors $[30,31]$.

The ultimate loads, taken as the maximum sustained load for each specimen, are presented in Table 1Table 1.

Table 1: Failure mode and ultimate load for each specimen.

\begin{tabular}{|c|c|c|c|c|c|c|}
\hline \multirow{3}{*}{$\begin{array}{l}\text { Geometry } \\
\text { of } \\
\text { specimen }\end{array}$} & \multirow{3}{*}{ Laminate } & \multirow{3}{*}{$\mathrm{N}$. } & \multirow{3}{*}{ Failure mode } & \multicolumn{3}{|c|}{ Ultimate Load $\left(L_{u}\right)$} \\
\hline & & & & $\begin{array}{c}\text { Individual } \\
\text { value }\end{array}$ & Avg. & $\mathrm{CV}$ \\
\hline & & & & {$[\mathrm{kN}]$} & {$[\mathrm{kN}]$} & [\%] \\
\hline \multirow{12}{*}{ BEL } & \multirow{3}{*}{ CSM } & 01 & cleavage & 6.27 & \multirow{3}{*}{6.51} & \multirow{3}{*}{5.3} \\
\hline & & 02 & cleavage & 6.90 & & \\
\hline & & 03 & cleavage & 6.35 & & \\
\hline & \multirow{3}{*}{ BIA } & 01 & cleavage & 6.20 & \multirow{3}{*}{6.28} & \multirow{3}{*}{1.5} \\
\hline & & 02 & cleavage & 6.25 & & \\
\hline & & 03 & cleavage & 6.39 & & \\
\hline & \multirow{3}{*}{ MU2 } & 01 & cleavage & 6.54 & \multirow{3}{*}{6.22} & \multirow{3}{*}{8.7} \\
\hline & & 02 & cleavage & 5.59 & & \\
\hline & & 03 & cleavage & 6.53 & & \\
\hline & \multirow{3}{*}{ MU4 } & 01 & cleavage & 13.28 & \multirow{3}{*}{12.96} & \multirow{3}{*}{2.5} \\
\hline & & 02 & cleavage & 12.96 & & \\
\hline & & 03 & cleavage & 12.63 & & \\
\hline \multirow{13}{*}{ LAT } & \multirow{4}{*}{ CSM } & 01 & bearing + net-tension & 7.04 & \multirow{4}{*}{9.74} & \multirow{4}{*}{21.1} \\
\hline & & 02 & bearing + net-tension & 11.91 & & \\
\hline & & 03 & bearing & 10.49 & & \\
\hline & & 04 & bearing + net-tension & 9.50 & & \\
\hline & \multirow{3}{*}{ BIA } & 01 & bearing + net-tension & 11.32 & \multirow{3}{*}{11.06} & \multirow{3}{*}{4.0} \\
\hline & & 02 & bearing + net-tension & 11.32 & & \\
\hline & & 03 & bearing + net-tension & 10.54 & & \\
\hline & \multirow{3}{*}{ MU2 } & 01 & bearing & 12.17 & \multirow{3}{*}{12.24} & \multirow{3}{*}{7.7} \\
\hline & & 02 & bearing + net-tension & 13.22 & & \\
\hline & & 03 & bearing & 11.34 & & \\
\hline & \multirow{3}{*}{ MU4 } & 01 & bearing + net-tension & 24.53 & \multirow{3}{*}{26.93} & \multirow{3}{*}{12.7} \\
\hline & & 02 & bearing + net-tension & 29.37 & & \\
\hline & & 03 & bearing + net-tension & 26.89 & & \\
\hline
\end{tabular}

Apart the laminate MU4, small variation on ultimate load was observed between specimens fabricated with different types of laminates (see Table 1Table 1). The ratios between the average ultimate loads of BEL specimens comprising other types of laminates and the CSM laminate was: 0.96, 0.95 and 1.99, for BIA, MU2 and MU4 laminates, respectively. For LAT specimens the respective ratios were: 1.13, 1.26 and 2.76. The higher ultimate load 
of MU4 in both specimen geometries (BEL and LAT) was due to its larger sectional area. In fact, while the ultimate loads obtained for the BEL and LAT specimens comprising MU2 laminate were, respectively, $6.22 \mathrm{kN}$ and $12.24 \mathrm{kN}$, the average ultimate load obtained for the correspondent MU4 specimens were $12.96 \mathrm{kN}$ and $26.93 \mathrm{kN}$, that is, a factor 1.97 and 2.08 for the BEL and LAT specimens. These factors were similar to the ratio between the thicknesses of MU4 and MU2, that was equal to 1.82 .

Attention is paid to the fact that different failure modes led to similar ultimate loads in the LAT specimens made of CSM and MU2 laminates (see Table 1Table 1). This behaviour may indicate that for these specimens the bearing strength and the tensile strength in the net-section were achieved for similar load levels.

By comparing the ultimate loads of BEL and LAT specimens (see Table 1Table 1), it was verified that for all tested laminates the failure by cleavage (BEL specimens) happens at a load level lower than the ultimate load corresponding to the bearing/net-tension failure on LAT specimens. The ratios between the average ultimate loads obtained by the LAT specimens and by the BEL specimens were equal to $1.50,1.76,1.97$ and 2.08 to CSM, BIA, MU2 and MU4 laminates, respectively. This behaviour is consistent with that observed by the authors in the pull-out tests with GFRP connectors embedded in SFRSCC in the first part of this paper [3]. In fact, in the pull-out tests with perforated plate connector comprising CSM composite, failure usually occurred within the GFRP connector by cleavage immediately below the holes. Net-section failure only occurred in few cases. No bearing failure was observed for the specimens geometries tested in the pull-out tests.

By comparing the results obtained in the laminates BIA and MU2 (see Table 1Table 1) is possible to conclude that for the studied fibre content, there was no relevant contribution of the fibres that are parallel and perpendicular to the load direction on the bearing strength of the connection, independently of the failure mode expected: cleavage or bearing. Moreover, the similar load capacity of the specimens failing by cleavage, regardless the type of laminate, suggested that for the geometry studied the load capacity was conditioned by the resin strength, not by the fibre content, type or arrangement. Such observed behaviour diverges from that found in the literature [32]. This probably happens due to the particular geometry of the specimens adopted in this work, that was set based on the constrains imposed by the geometry of the structural elements where the PERFOFRP connector is going to be applied.

By comparing the ultimate loads obtained in the tests with BEL and LAT specimens, it can be concluded that, independently of the laminate used, the geometric configuration proposed for the connector in the experimental program presented in the first part of this paper [3] was more prone to suffer a failure by cleavage immediately below the hole than a net-tension failure or even a bearing failure. Thus, it can be concluded that, for the materials and geometries studied in this research, the strength capacity of the proposed connectors was limited by the distance between lateral extremities of the hole and the below free edge of specimen (distance $e$ indicated in Figure 3 Figure 
3). In the case of the proposed connectors, this distance was conditioned by the thickness of the SFRSCC layers of the sandwich panels [33], and a value of $22.5 \mathrm{~mm}$ was adopted $\left(7.5 \mathrm{~mm}+D_{h} / 2\right)$.

\subsection{Strains}

Table 2Table 2 provides a summary of the experimental data in terms of maximum strains measured in the grosssection of laminate of all the specimens (in the reference length of the clip-gauge). The results indicated that in the BEL specimens a maximum of $77.8 \%$ of the elastic limit strain and $18.1 \%$ of the ultimate limit strain are attained respectively for one of the specimens comprised of MU4 and CSM laminates. Moreover, when LAT geometry was considered, apart from CSM laminate, all the other laminates present strains in the gross section higher than the elastic limit strain, attaining a maximum of $299.4 \%$ of the elastic limit strain in the BIA laminate. However, the strains were always lower than the ultimate limit strain of the respective laminates since failure at the gross-section was not observed in these laminates.

Table 2: Strain attained in the gross section of specimen.

\begin{tabular}{|c|c|c|c|c|c|c|c|}
\hline \multirow{3}{*}{$\begin{array}{l}\text { Geometry } \\
\text { of } \\
\text { specimen }\end{array}$} & \multirow{3}{*}{ Laminate } & \multicolumn{4}{|c|}{ Maximum gross strain $\left(\varepsilon_{\mathrm{gr}}\right)$} & \multirow[b]{2}{*}{$\varepsilon_{\mathrm{gr}} / \varepsilon_{\mathrm{pt.el}}$} & \multirow{3}{*}{$\varepsilon_{\mathrm{gr}} / \varepsilon_{\mathrm{pt.u}}$} \\
\hline & & N. & $\begin{array}{l}\text { Individual } \\
\text { value }\end{array}$ & Avg. & $\mathrm{CV}$ & & \\
\hline & & & {$[\mu \varepsilon]$} & {$[\mu \varepsilon]$} & {$[\%]$} & {$[\%]$} & \\
\hline \multirow{12}{*}{ BEL } & \multirow{3}{*}{ CSM } & 01 & 1908 & \multirow{3}{*}{2475} & \multirow{3}{*}{27.9} & 10.5 & 10.5 \\
\hline & & 02 & 3246 & & & 18.1 & 18.1 \\
\hline & & 03 & 2272 & & & 12.3 & 12.3 \\
\hline & \multirow{3}{*}{ BIA } & 01 & 2422 & \multirow{3}{*}{2388} & \multirow{3}{*}{7.6} & 24.5 & 1.4 \\
\hline & & 02 & 2549 & & & 25.9 & 1.5 \\
\hline & & 03 & 2193 & & & 21.9 & 1.3 \\
\hline & \multirow{3}{*}{ MU2 } & 01 & 1963 & \multirow{3}{*}{1924} & \multirow{3}{*}{15.5} & 47.9 & 9.5 \\
\hline & & 02 & 1607 & & & 32.9 & 6.5 \\
\hline & & 03 & 2201 & & & 47.0 & 9.3 \\
\hline & \multirow{3}{*}{ MU4 } & 01 & 2470 & \multirow{3}{*}{2800} & \multirow{3}{*}{35.8} & 56.5 & 10.6 \\
\hline & & 02 & 3927 & & & 77.8 & 14.6 \\
\hline & & 03 & 2003 & & & 39.0 & 7.3 \\
\hline \multirow{11}{*}{ LAT } & \multirow{4}{*}{ CSM } & 01 & 3388 & \multirow{4}{*}{4307} & \multirow{4}{*}{19.0} & 18.9 & 18.9 \\
\hline & & 02 & 4576 & & & 25.5 & 25.5 \\
\hline & & 03 & - & & & - & \\
\hline & & 04 & 4956 & & & 27.5 & 27.5 \\
\hline & \multirow{3}{*}{ BIA } & 01 & 29845 & \multirow{3}{*}{22232} & \multirow{3}{*}{30.7} & 299.4 & 17.1 \\
\hline & & 02 & 20227 & & & 203.2 & 11.6 \\
\hline & & 03 & 16625 & & & 167.0 & 9.6 \\
\hline & \multirow{3}{*}{ MU2 } & 01 & 8019 & & & 166.3 & 33.1 \\
\hline & & 02 & 8233 & 9389 & 23.3 & 171.5 & 34.1 \\
\hline & & 03 & 11914 & & & 248.3 & 49.4 \\
\hline & MU4 & 01 & 6547 & 9764 & 19.0 & 131.2 & 24.6 \\
\hline
\end{tabular}




\begin{tabular}{rrrr}
\hline 02 & 9175 & 232.2 & 43.5 \\
03 & 13569 & 271.0 & 50.7 \\
\hline
\end{tabular}

The shear-out stress versus local strain curves obtained from the surface strain gauges placed immediately below the holes of BEL specimens are shown in Figure 12Figure 12. From the results in this figure, the different ductility of both types of laminates for this loading conditions is quite visible. An initial linear response was observed followed by a branch that progressively becomes nonlinear. This nonlinear branch was, however, not observed in the CSM laminate. In fact, this laminate presented an almost linear relationship up to a brittle failure occurrence. In this test, the ultimate stress was attained for a strain approximately equal to $13500 \mu \varepsilon$. This value corresponds to $75 \%$ of ultimate limit strain obtained from the direct tensile tests with the laminate. This apparent premature failure may reflect the fact that the strain gauge was attached to the laminate at a distance of approximately $3 \mathrm{~mm}$ from the hole edge, while it was expected that the highest strain levels are developed immediately in the vicinity of the hole.

As might be expected from a knowledge of the direct tensile behaviour of the studied composites, the BIA laminate presented the most nonlinear response, and the MU2 and MU4 showed an almost bilinear response up to attain a pseudo-plastic phase (see Figure 12Figure $12 \mathrm{c}$ and d). This pseudo-plastic stage was also developed in BIA laminates after the ultimate limit strain was attained (see Figure 12Figure 12b).

The bearing stress versus local strain curves obtained from the longitudinal and transversal strain gauges are shown in Figure 13Figure 13. By comparing the readings from strain gauges symmetrically positioned in laminates, it can be concluded the out-of-plane deformation was almost null (see Figure 13Figure 13a to Figure 13Figure 13e). Apart from CSM specimens, the remaining specimens exhibited a pronounced nonlinear behaviour. For the CSM and MU2 unloading was observed in a stage when the strain level in the lateral vicinity of the hole was much lower than the ultimate limit strain of the respective laminates (see Figure 13Figure 13a and Figure 13Figure 13c). After this unloading occurrence, the initial stress-strain trend was not maintained and a reduction in the strains in the CSM specimen was observed (see Figure 13Figure 13a). In the MU2 specimen, an asymmetric behaviour was noticed after the unloading (see Figure 13Figure 13c). These responses can be justified by considering the damage configuration in specimens shown in Figure 9Figure 9, since it was caused by the progressive failure by bearing. This reduction of strain level at the lateral vicinity of the holes was expected to happen, once the hole was elongated down by bearing, leading to maximum strains occurring in the region located near the pin. 


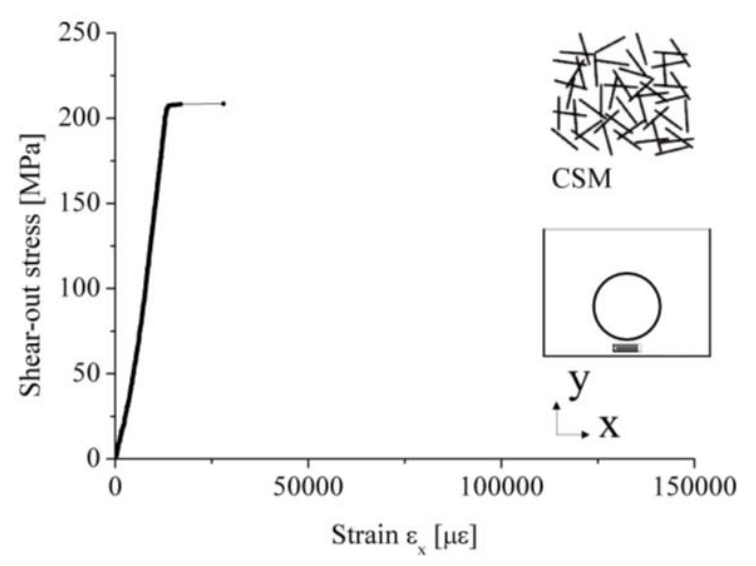

(a)

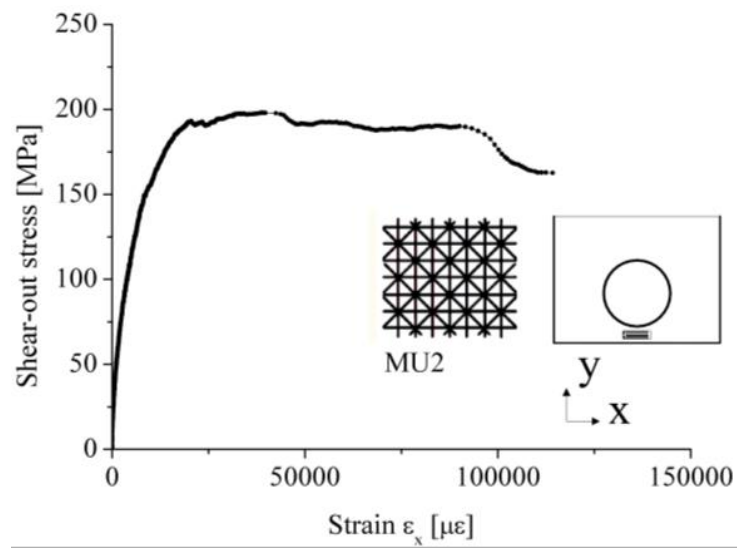

(c)

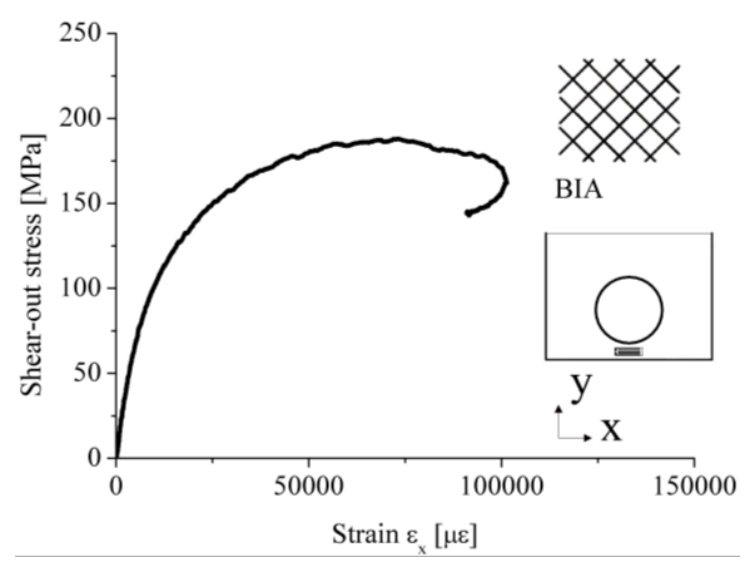

(b)

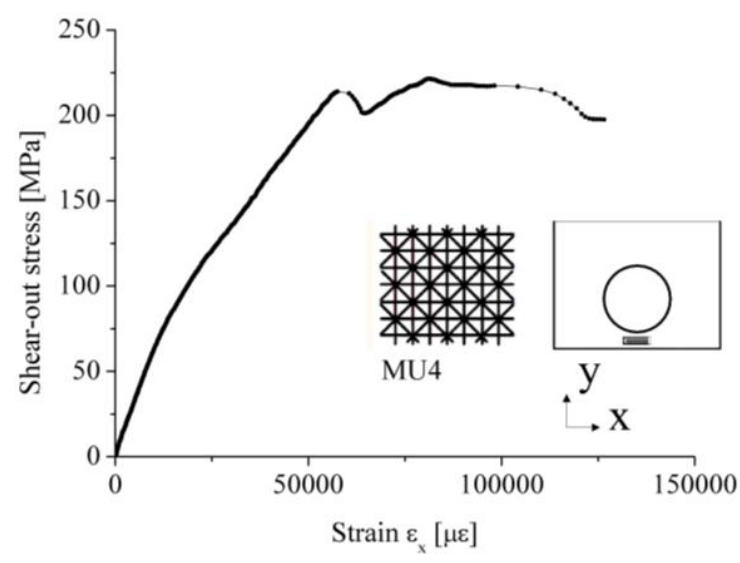

(d)

Figure 12: Shear-out stress vs. engineering strain $\varepsilon x$ in the proximity of hole corresponding to BEL specimens. Laminates: (a) CSM; (b) BIA; (c) MU2; (d) MU4.

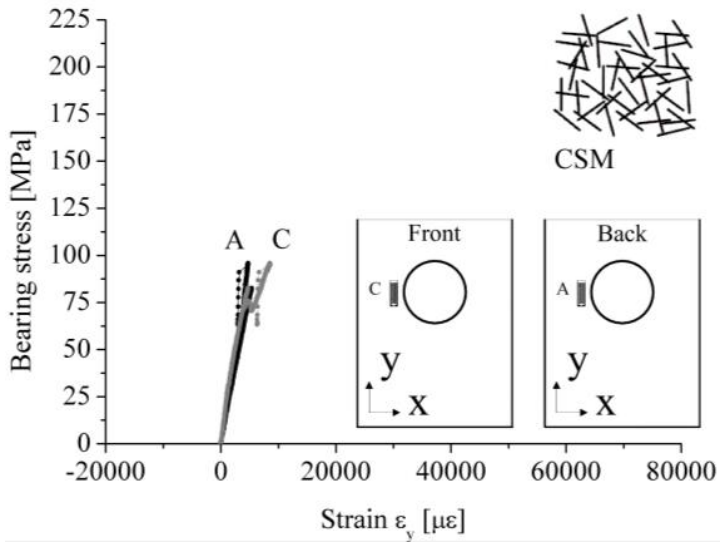

(a)

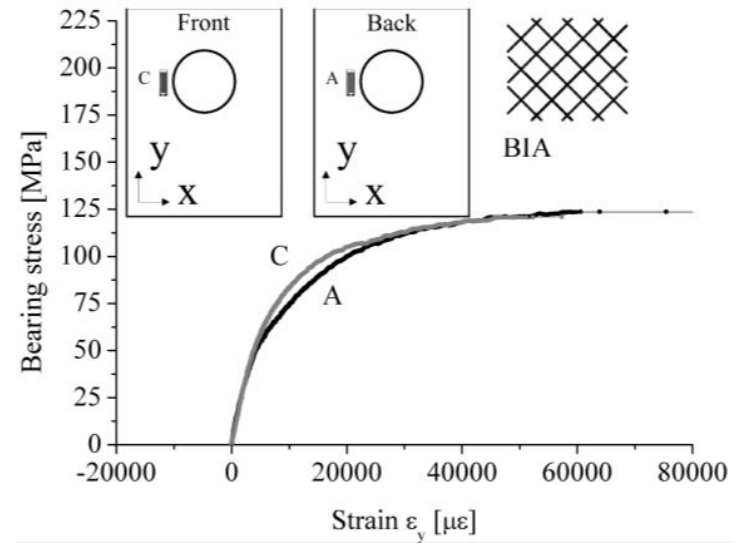

(b) 


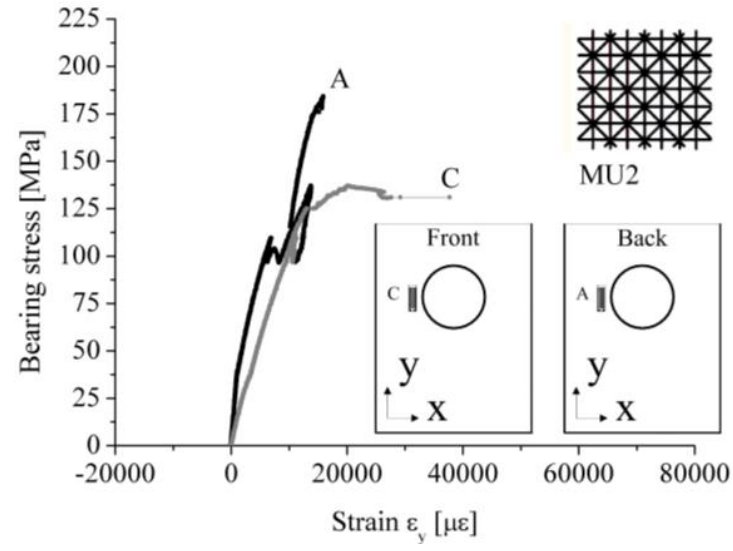

(c)

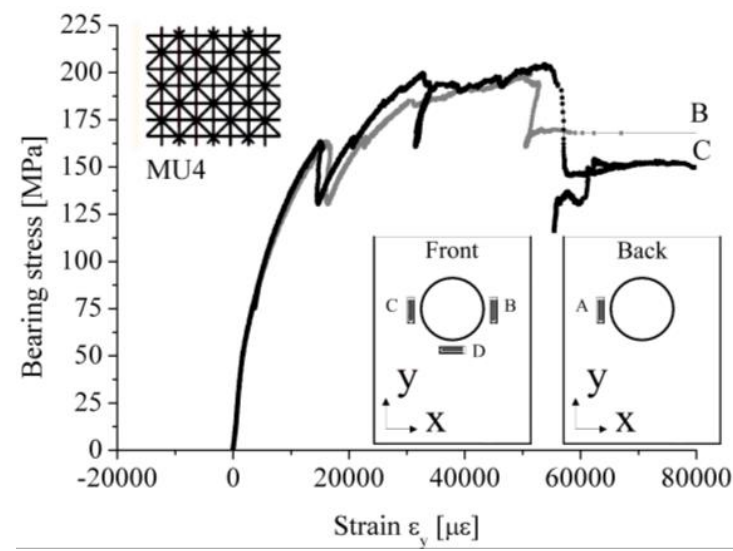

(e)

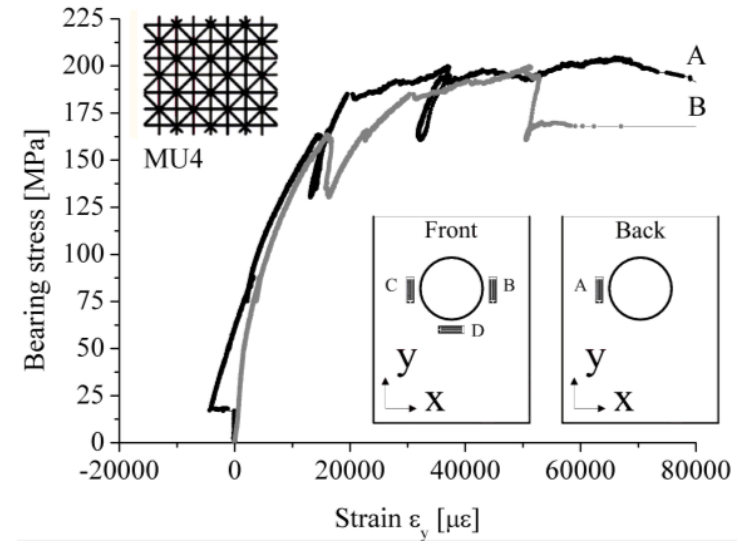

(d)

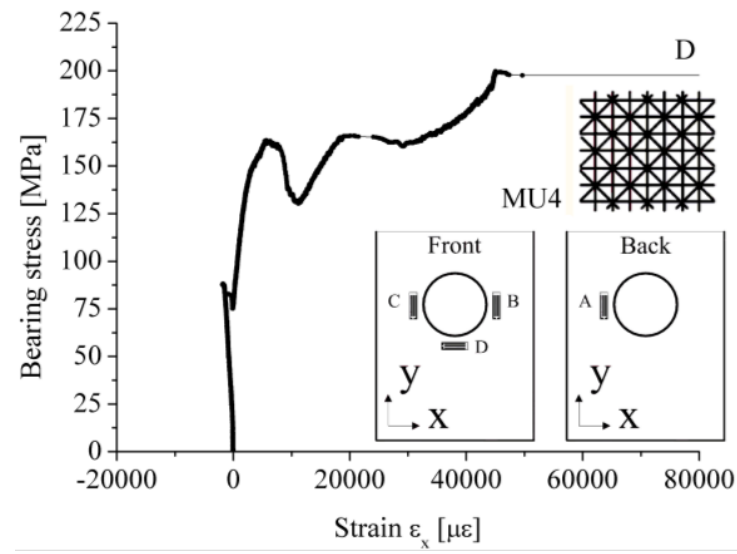

(f)

Figure 13: Bearing stress vs. engineering strain in the proximity of hole corresponding to LAT specimens:

(a) CSM; (b) BIA; (c) MU2; (d) MU4 - front and back; (e) MU4 - left and right; (f) MU4 - below.

Strain fields during the loading process were obtained for all the specimens using Digital Image Correlation (DIC) technique. Figure 14Figure 14 and Figure 15Figure 15 represent the variations of strain fields on a BEL specimens, while the variations of strain fields on LAT specimens are presented in Figure 16Figure 16 and Figure 17Figure 17.

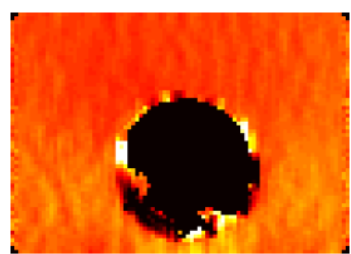

(a)

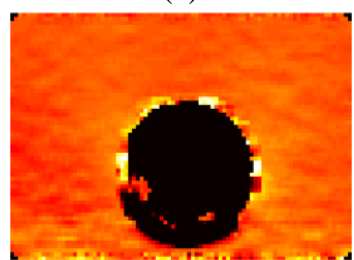

(d)

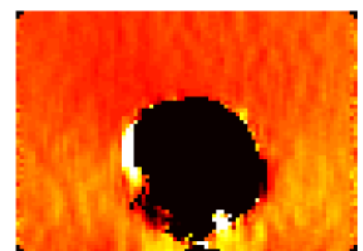

(b)

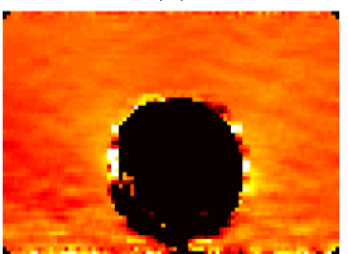

(e)

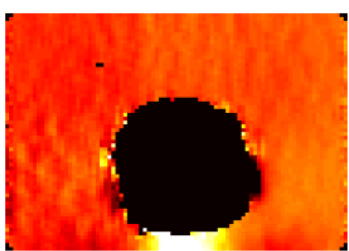

(c)

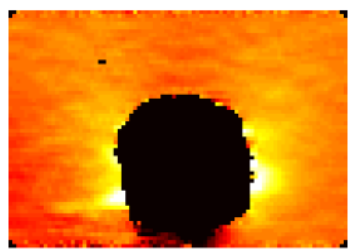

(f)

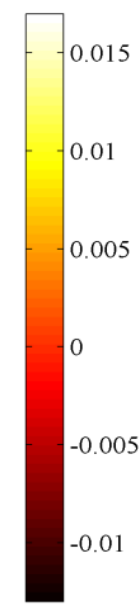

Figure 14: Engineering strain field evolving along the test for a BEL/CSM specimen. (a) $\varepsilon_{x}\left(50 \%\right.$ of $\left.F_{\max }\right)$; (b) $\varepsilon_{x}$ 
(75\% of $\left.F_{\max }\right) ;(\mathrm{c}) \varepsilon_{x}\left(100 \%\right.$ of $\left.F_{\max }\right) ;(\mathrm{d}) \varepsilon_{y}\left(50 \%\right.$ of $\left.F_{\max }\right) ;(\mathrm{e}) \varepsilon_{y}\left(75 \%\right.$ of $\left.F_{\max }\right) ;(\mathrm{f}) \varepsilon_{y}\left(100 \%\right.$ of $\left.F_{\max }\right)$. Units: [ ]. Normal compression strain is positive.

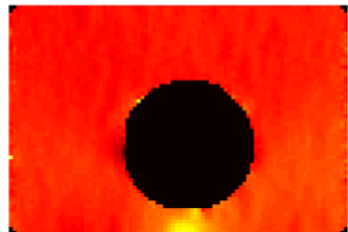

(a)

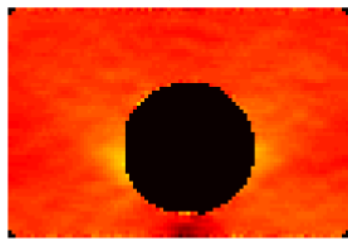

(d)

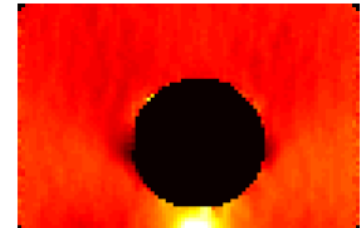

(b)

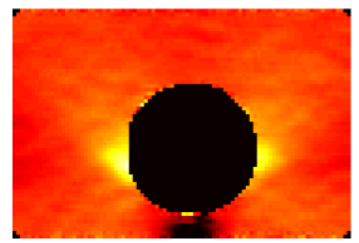

(e)

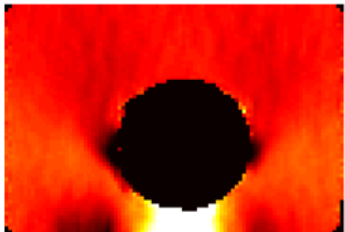

(c)

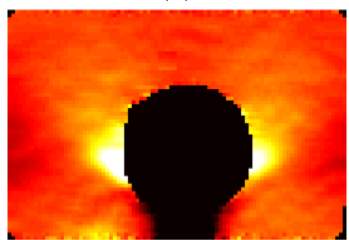

(f)

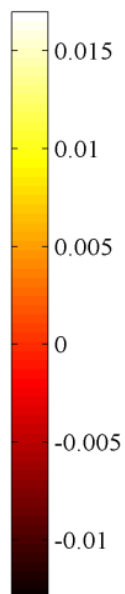

Figure 15: Engineering strain field evolving along the test for a BEL/MU2 specimen. (a) $\varepsilon_{x}\left(50 \%\right.$ of $F_{\max }$ ); (b) $\varepsilon_{x}$ $\left(75 \%\right.$ of $\left.F_{\max }\right) ;(\mathrm{c}) \varepsilon_{x}\left(100 \%\right.$ of $\left.F_{\max }\right) ;(\mathrm{d}) \varepsilon_{y}\left(50 \%\right.$ of $\left.F_{\max }\right) ;(\mathrm{e}) \varepsilon_{y}\left(75 \%\right.$ of $\left.F_{\max }\right)$; (f) $\varepsilon_{y}\left(100 \%\right.$ of $\left.F_{\max }\right)$. Units: [ ]. Normal compression strain is positive.

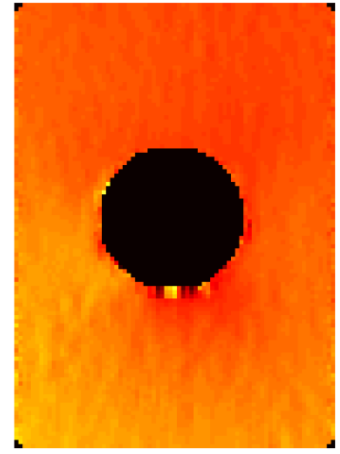

(a)

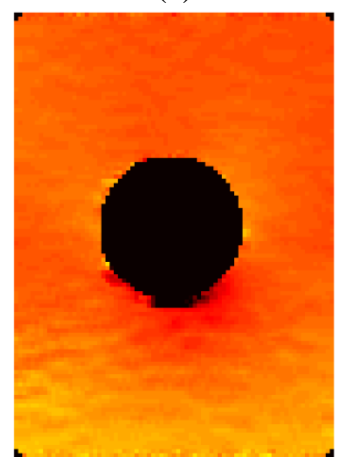

(d)

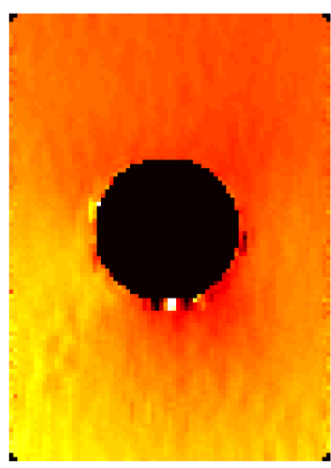

(b)

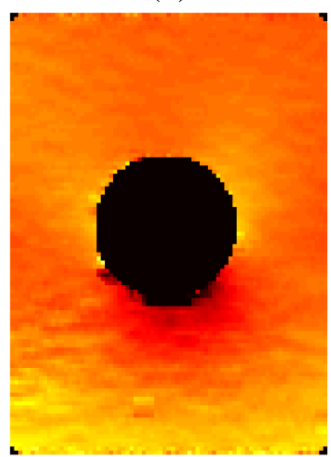

(e)

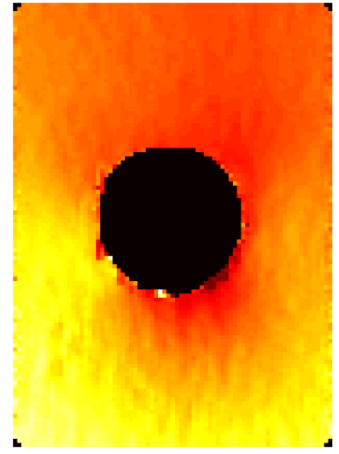

(c)

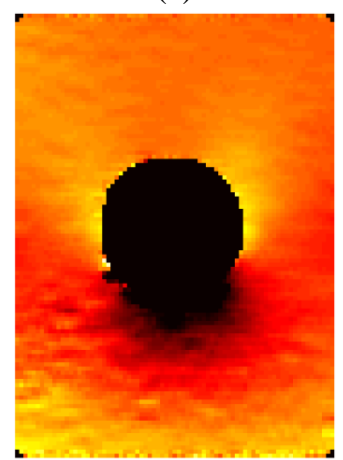

(f)

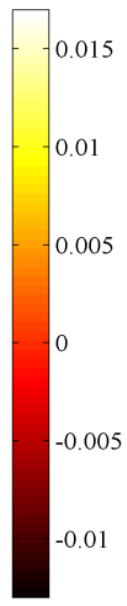

Figure 16: Engineering strain field evolving along the test for a LAT/CSM specimen. (a) $\varepsilon_{x}\left(50 \%\right.$ of $F_{\max }$ ); (b) $\varepsilon_{x}$ (75\% of $\left.F_{\max }\right)$; (c) $\varepsilon_{x}\left(100 \%\right.$ of $\left.F_{\max }\right) ;(\mathrm{d}) \varepsilon_{y}\left(50 \%\right.$ of $\left.F_{\max }\right) ;(\mathrm{e}) \varepsilon_{y}\left(75 \%\right.$ of $\left.F_{\max }\right)$; (f) $\varepsilon_{y}\left(100 \%\right.$ of $\left.F_{\max }\right)$. Units: []. Normal compression strain is positive. 


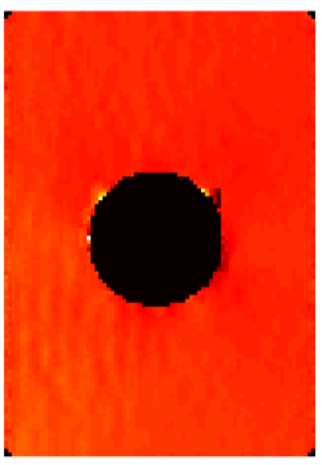

(a)

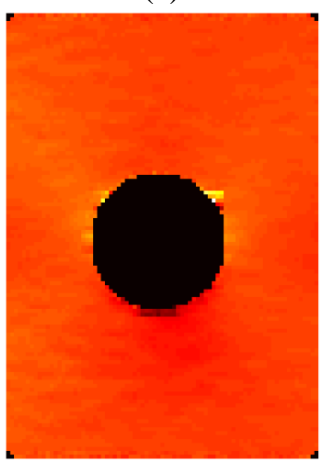

(d)

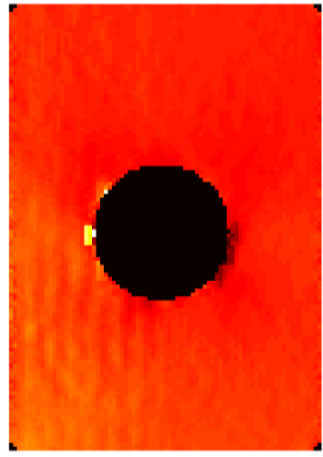

(b)

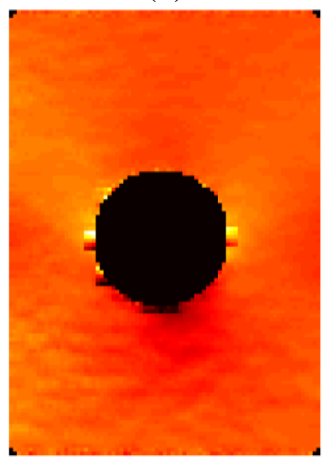

(e)

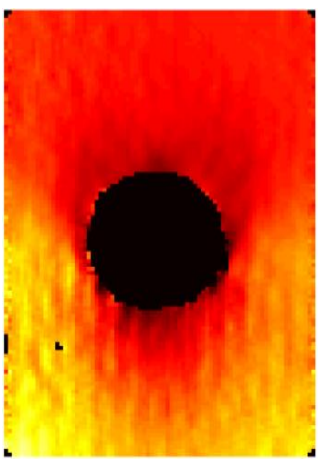

(c)

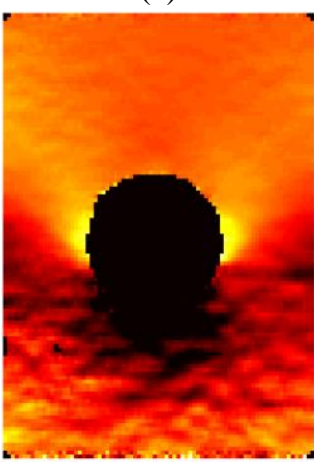

(f)

Figure 17: Engineering strain field evolving along the test for a LAT/MU2 specimen. (a) $\varepsilon_{x}\left(50 \%\right.$ of $F_{\max }$ ); (b) $\varepsilon_{x}$ (75\% of $\left.F_{\max }\right) ;(\mathrm{c}) \varepsilon_{x}\left(100 \%\right.$ of $\left.F_{\max }\right) ;(\mathrm{d}) \varepsilon_{y}\left(50 \%\right.$ of $\left.F_{\max }\right) ;(\mathrm{e}) \varepsilon_{y}\left(75 \%\right.$ of $\left.F_{\max }\right) ;(\mathrm{f}) \varepsilon_{y}\left(100 \%\right.$ of $F_{\max }$. Units: [ ]. Normal compression strain is positive.

The engineering normal and shear strain diagrams along 4 representative sections (L1 to L4), for different load levels, are presented in Figure 18Figure 18 to Figure 21Figure 21 for BEL specimens and Figure 20Figure 20 and Figure 21Figure 21 for LAT specimens.

For all the specimens, it is clear that the loading leads to an increasingly higher strain concentration at the $y$-direction in the nearby the hole, along section L1 (see Figure 18Figure 18a, Figure 19Figure 19a, Figure 20Figure $20 \mathrm{a}$ and Figure 21Figure 21a). In this case, the strain values in BEL/CSM specimens were a little higher than the strain values measured in BEL/MU2 specimens. Nonetheless, for BEL specimens, the highest tensile normal strains were found for at $x$-direction along the line L3, between the hole and the bottom edge (see Figure 18Figure 18b and Figure 19Figure 19b). In L3 alignment, the tensile normal strains were higher in BEL/MU2 specimens than in BEL/CSM specimens. This pattern is coherent to the failure modes obtained for this type of specimen. Furthermore, it is clear in Figure 19Figure 19b that there was some flexure in the region below the hole, with higher tensile strains in the nearby of the bottom edge of specimen. Shear strains along lines L2 and L4 present similar magnitude in BEL/MU2 specimen (see Figure 19Figure 19e and Figure 19Figure 19f), indicating that the test was performed in a symmetric way. The same does not happen for the BEL/CSM specimen (see Figure 18Figure 18e and f). 


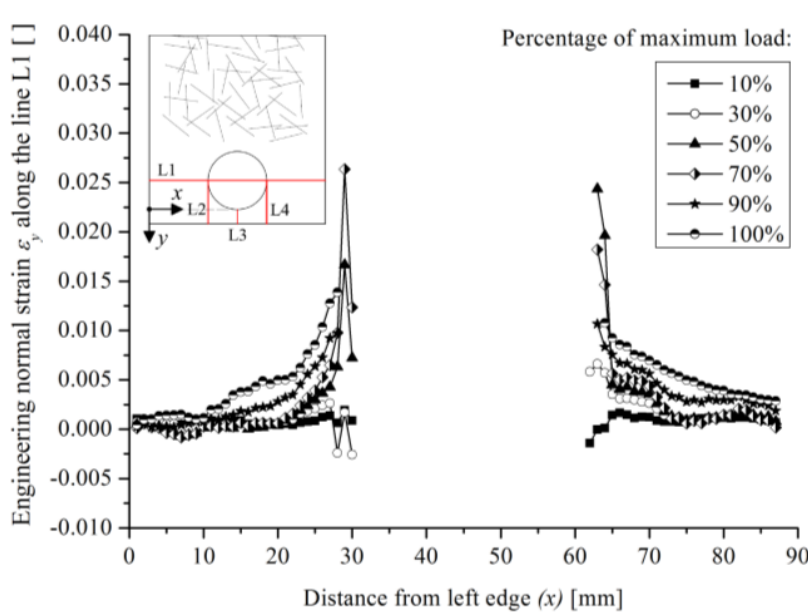

(a)

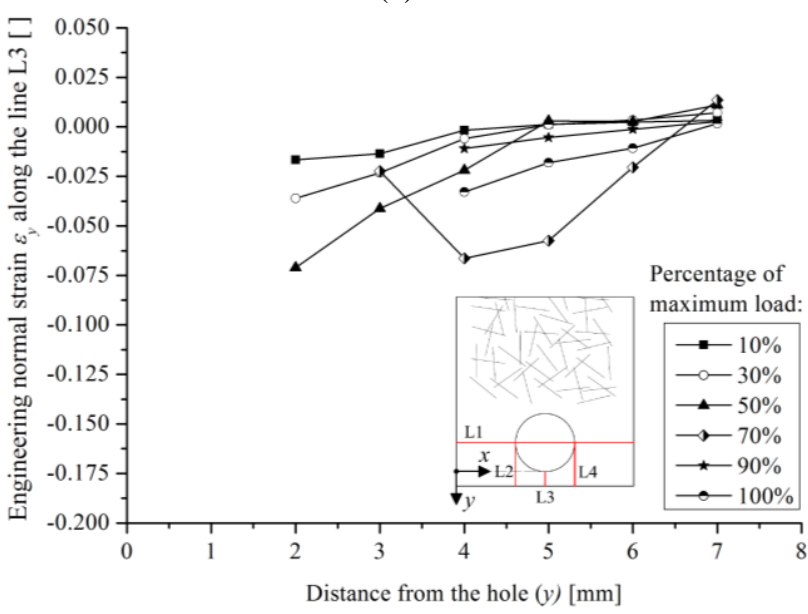

(c)

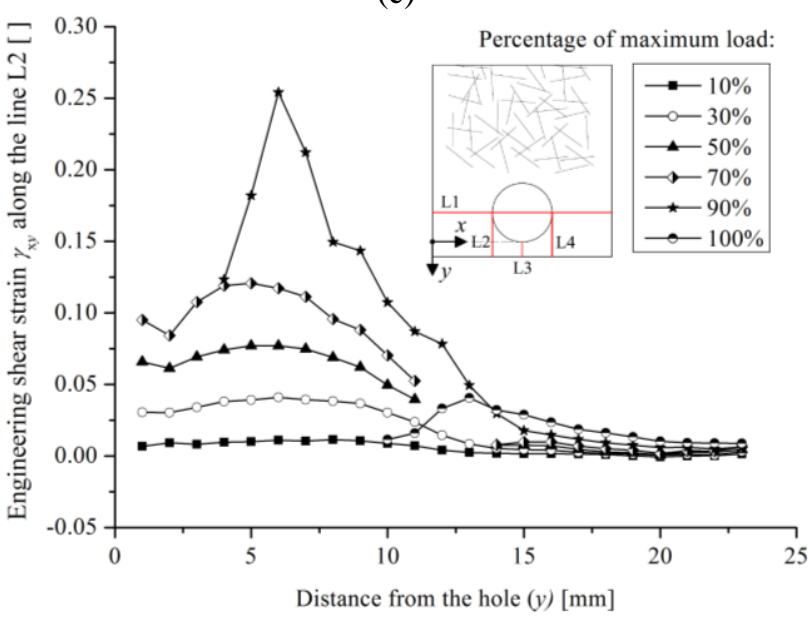

(e)

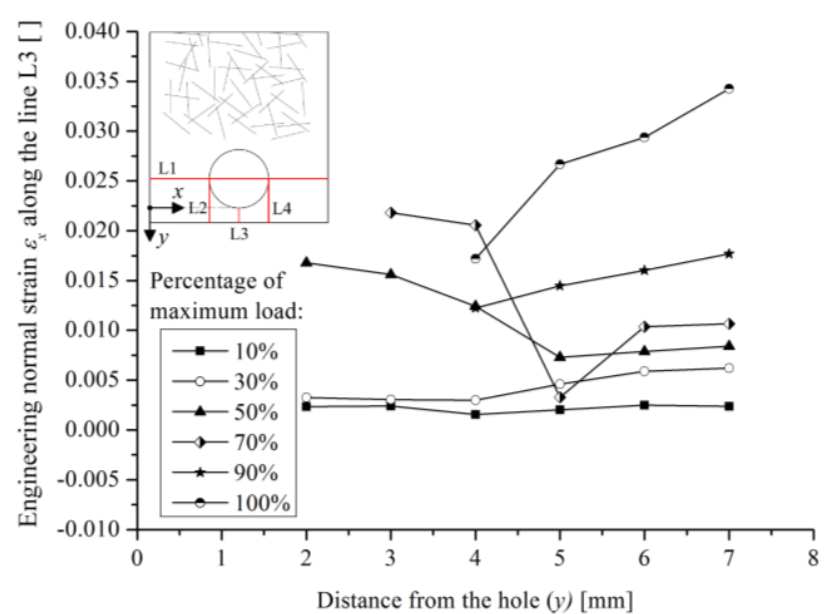

(b)

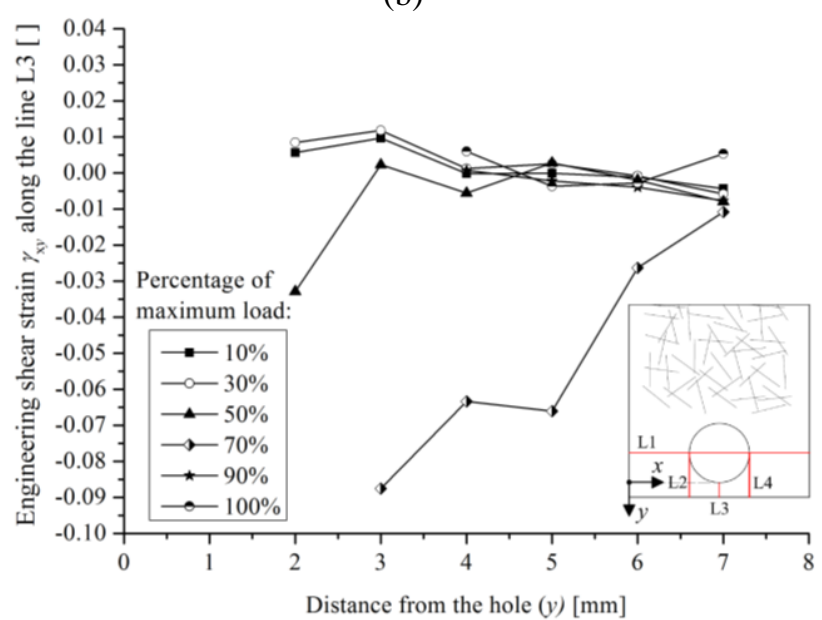

(d)

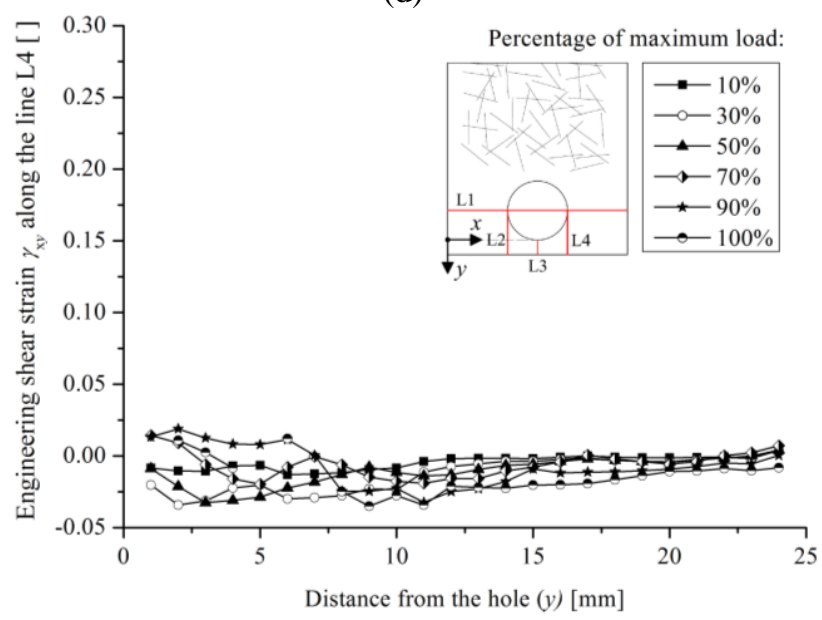

(f)

Figure 18: Engineering strain evolving along representative lines for a BEL/CSM specimen: (a) $\varepsilon_{y}$ along line L1; (b) $\varepsilon_{x}$ along line L3; (c) $\varepsilon_{y}$ along line L3; (d) $\gamma_{x y}$ along line L3; (e) $\gamma_{x y}$ along line L2; (f) $\gamma_{x y}$ along line L4. Normal compression strain is positive. Shear strain is positive if it represents a decrease on the angle between the sides of an element of material lying parallel to the positive $x$ and $y$ axes. 


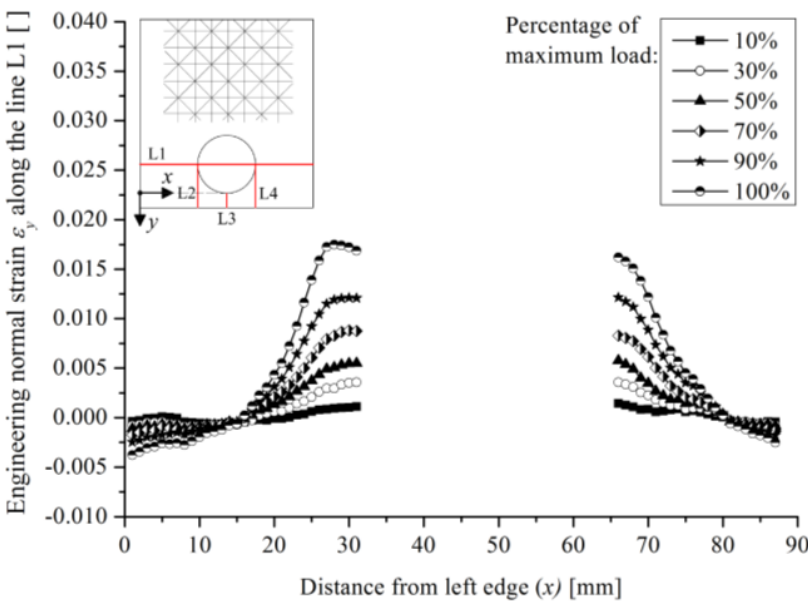

(a)

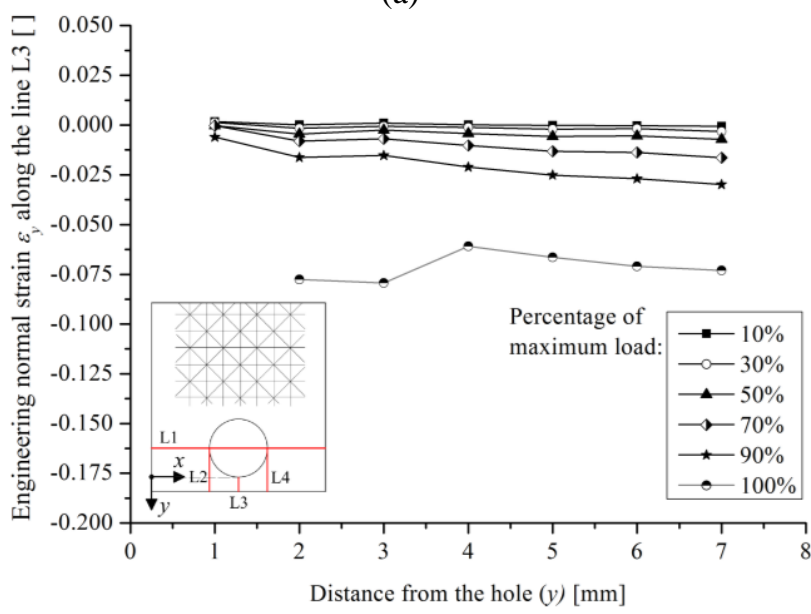

(c)

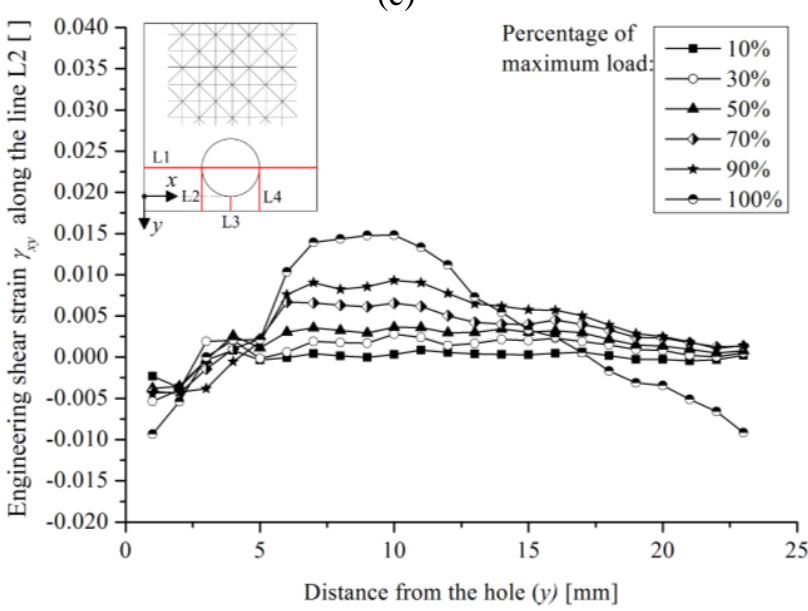

(e)

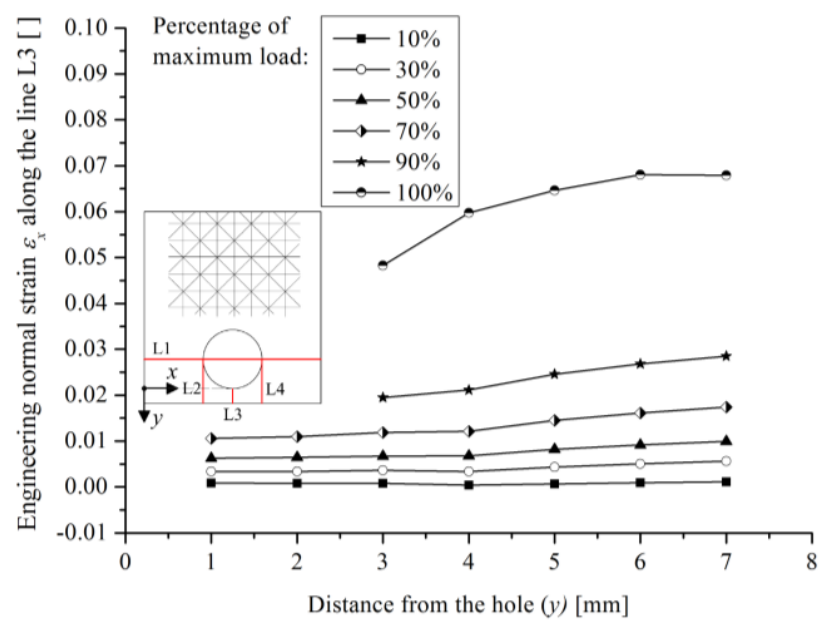

(b)

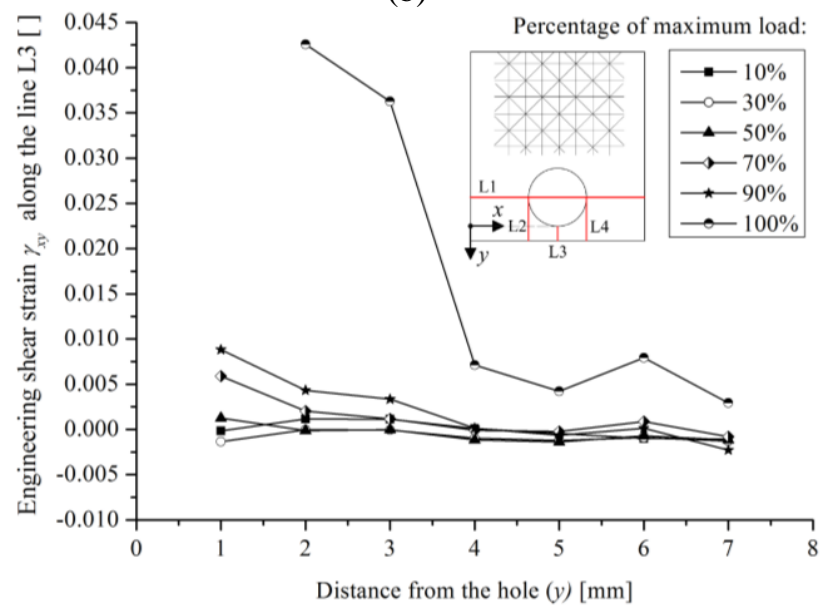

(d)

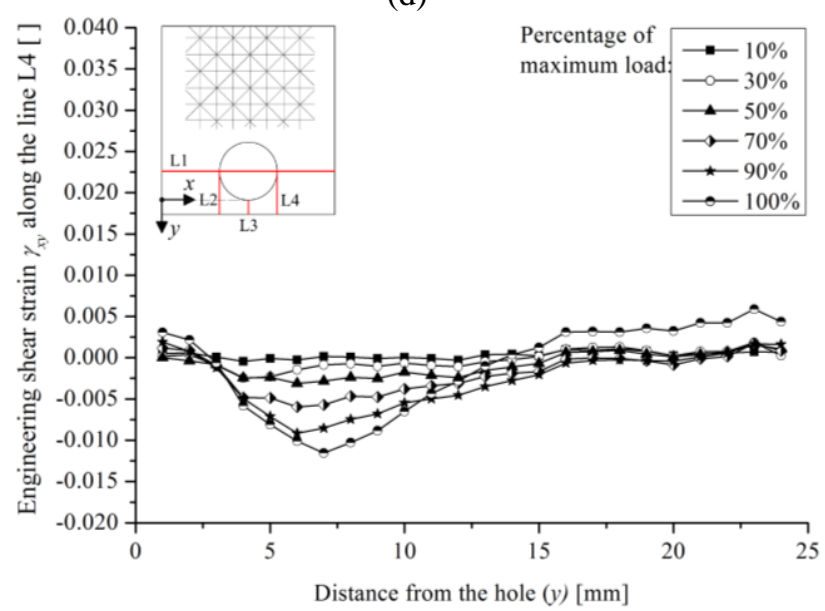

(f)

Figure 19: Engineering strain evolving along representative lines for a BEL/MU2 specimen: (a) $\varepsilon_{y}$ along line L1; (b) $\varepsilon_{x}$ along line L3; (c) $\varepsilon_{y}$ along line L3; (d) $\gamma_{x y}$ along line L3; (e) $\gamma_{x y}$ along line L2; (f) $\gamma_{x y}$ along line L4. Normal compression strain is positive. Shear strain is positive if it represents a decrease on the angle between the sides of an element of material lying parallel to the positive $x$ and $y$ axes. 

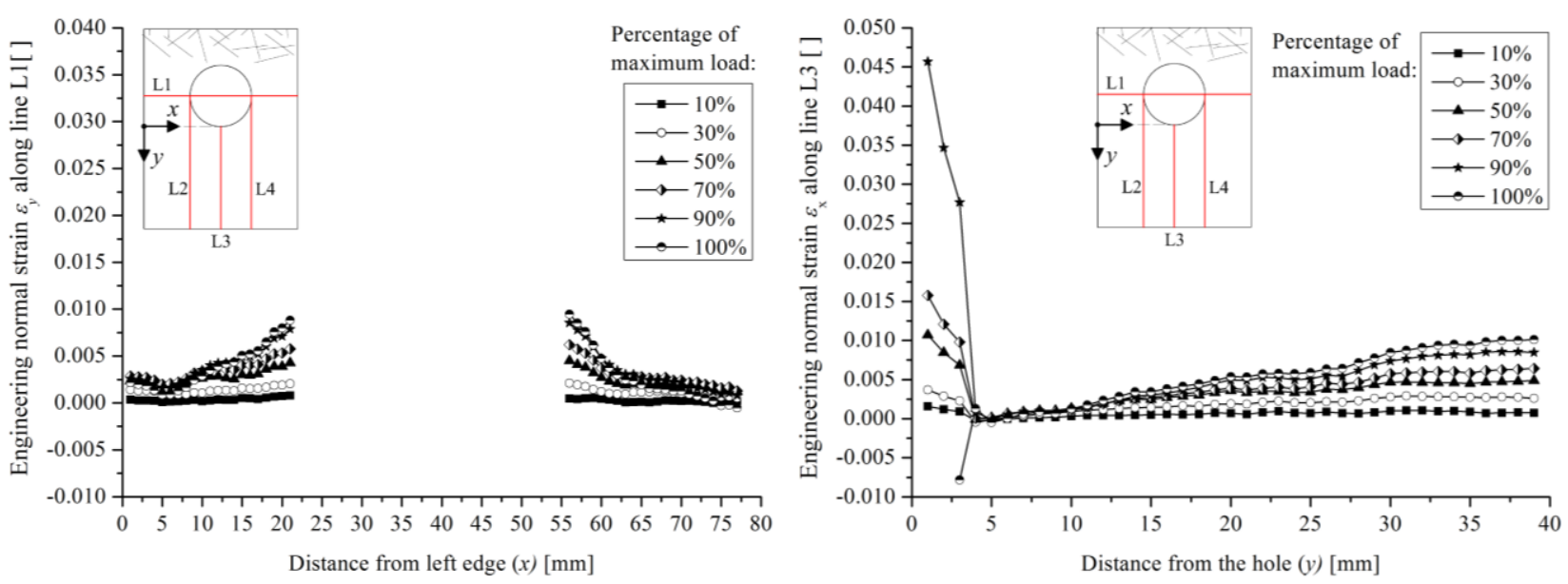

(a)
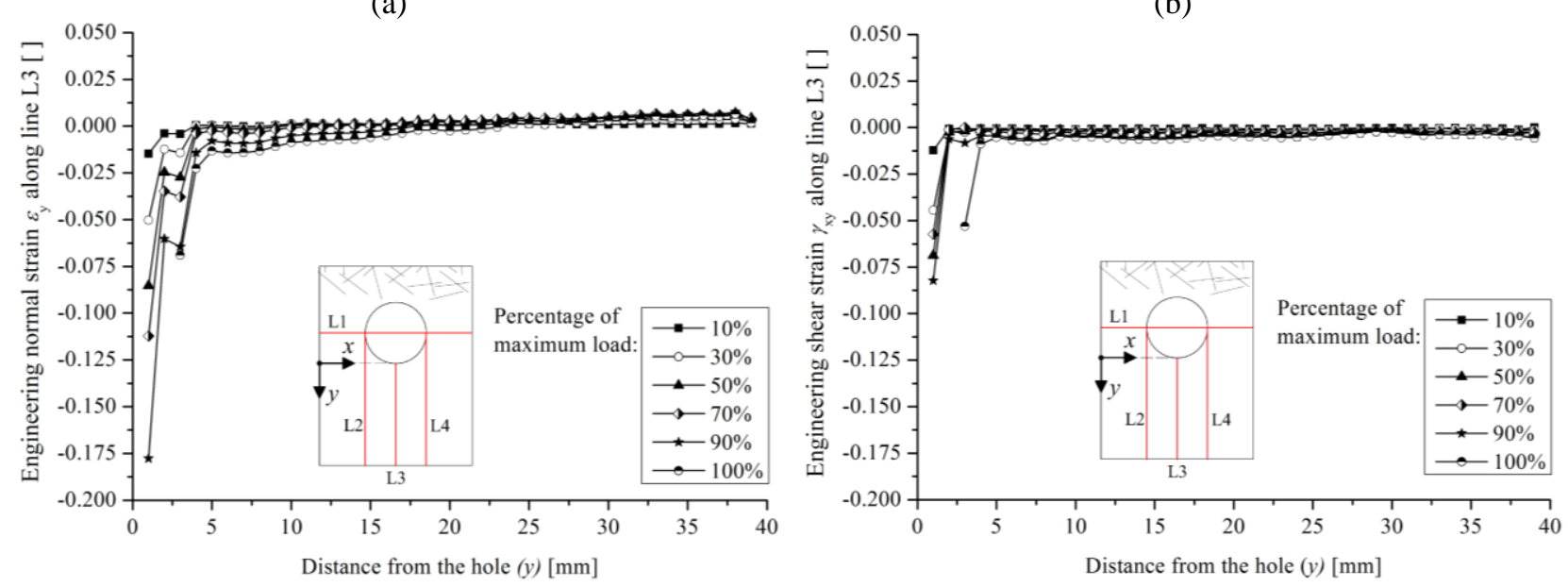

(c)

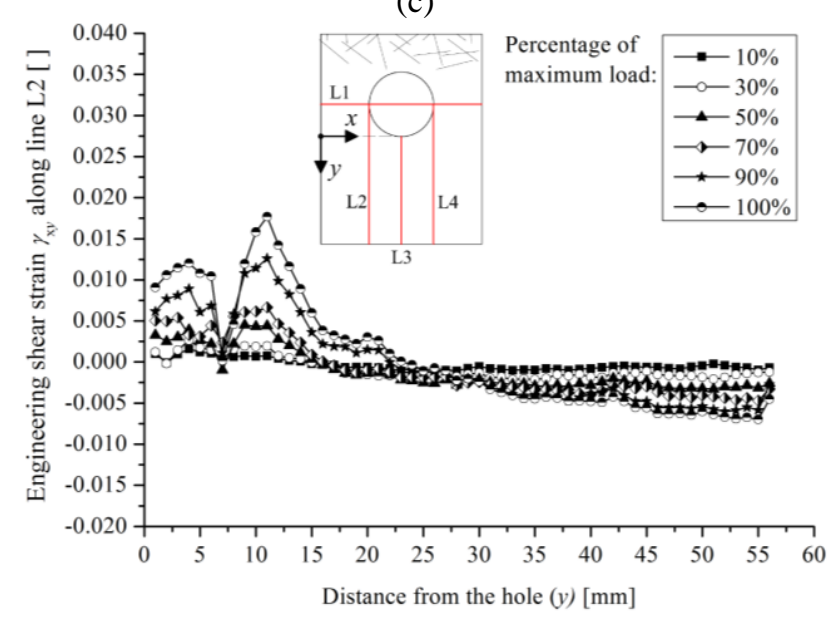

(e) (d)

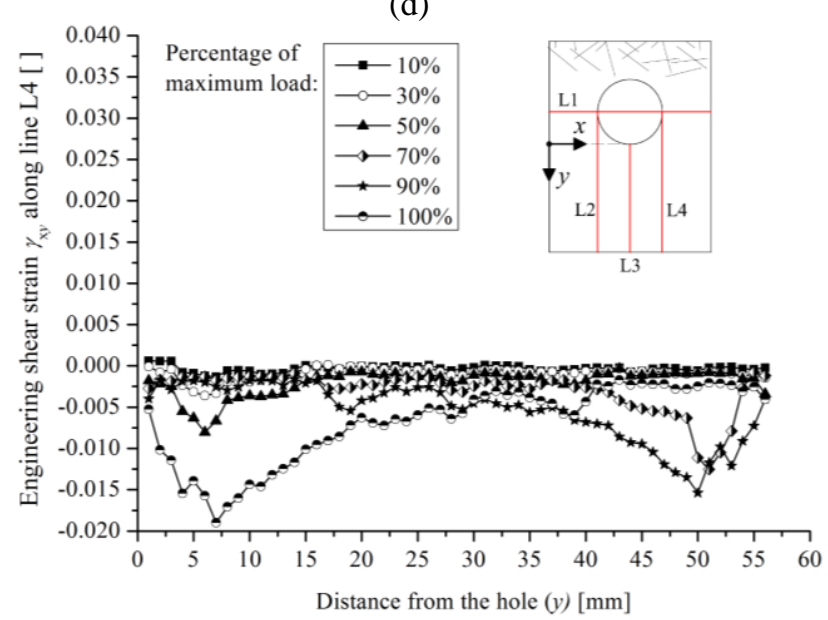

(f)

Figure 20: Engineering strain evolving along representative lines for a LAT/CSM specimen: (a) $\varepsilon_{y}$ along line L1; (b) $\varepsilon_{x}$ along line L3; (c) $\varepsilon_{y}$ along line L3; (d) $\gamma_{x y}$ along line L3; (e) $\gamma_{x y}$ along line L2; (f) $\gamma_{x y}$ along line L4. Normal compression strain is positive. Shear strain is positive if it represents a decrease on the angle between the sides of an element of material lying parallel to the positive $x$ and $y$ axes. 

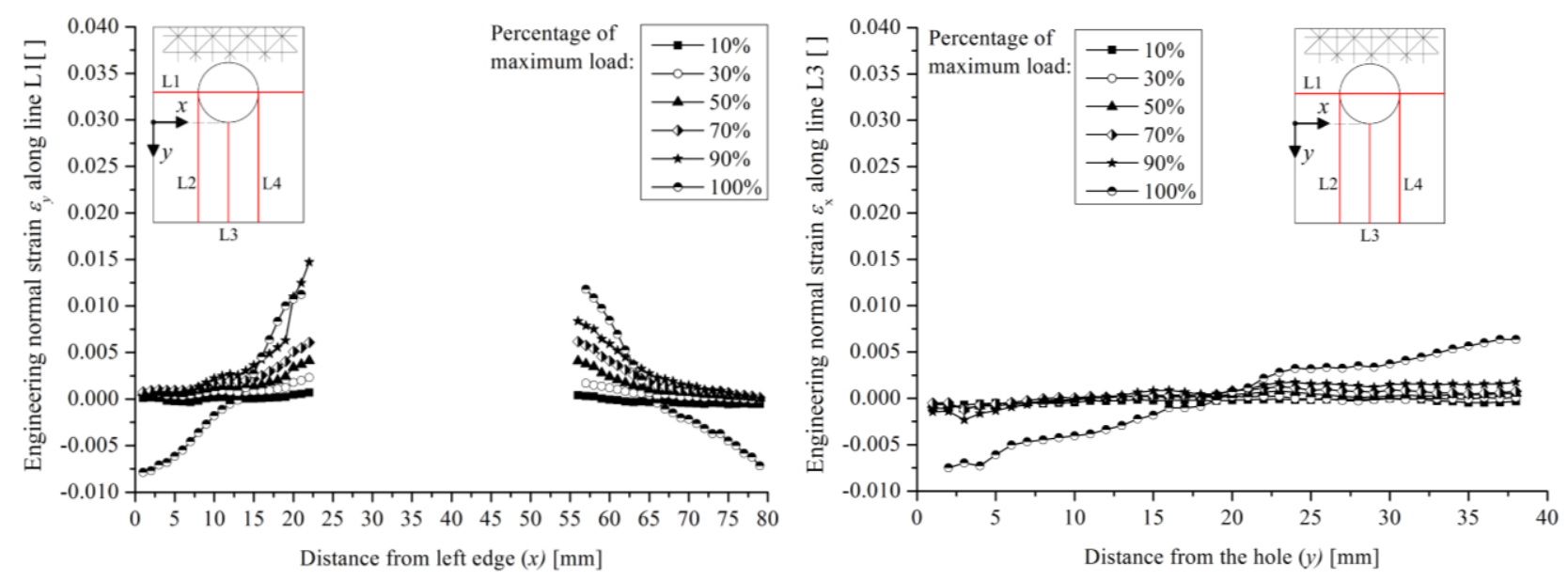

(a)
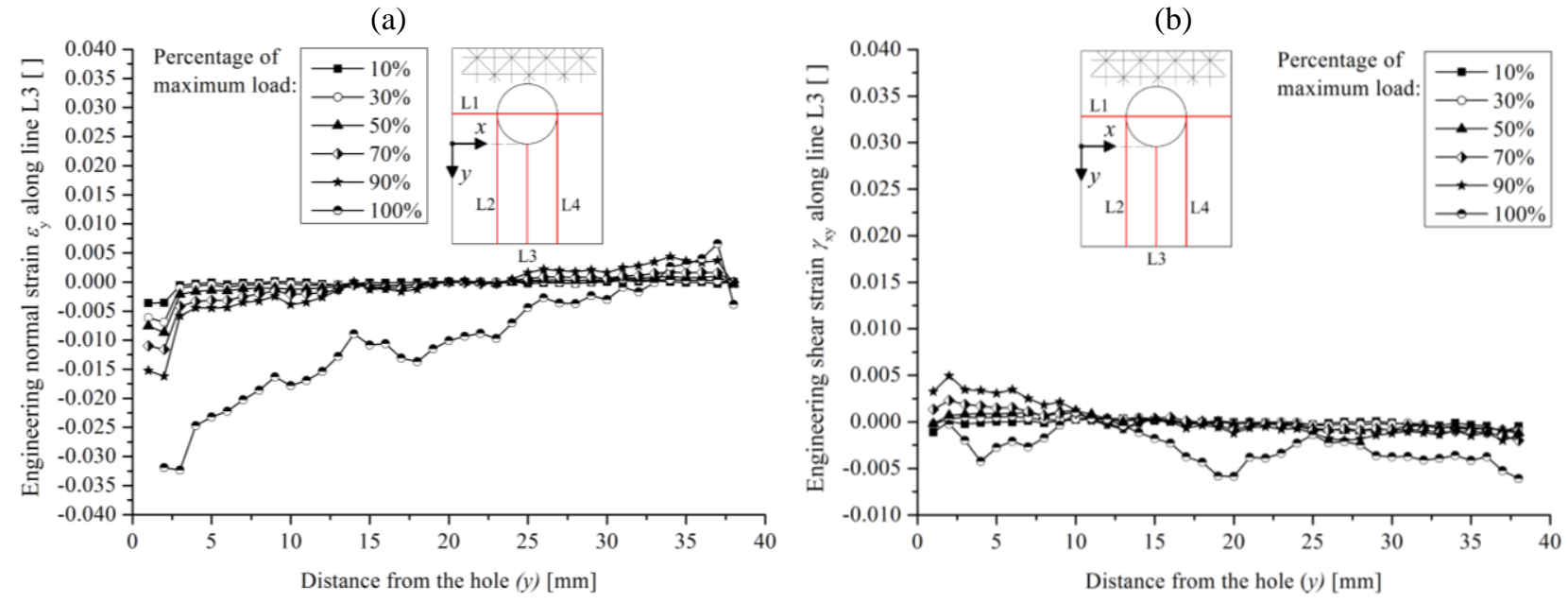

(c)

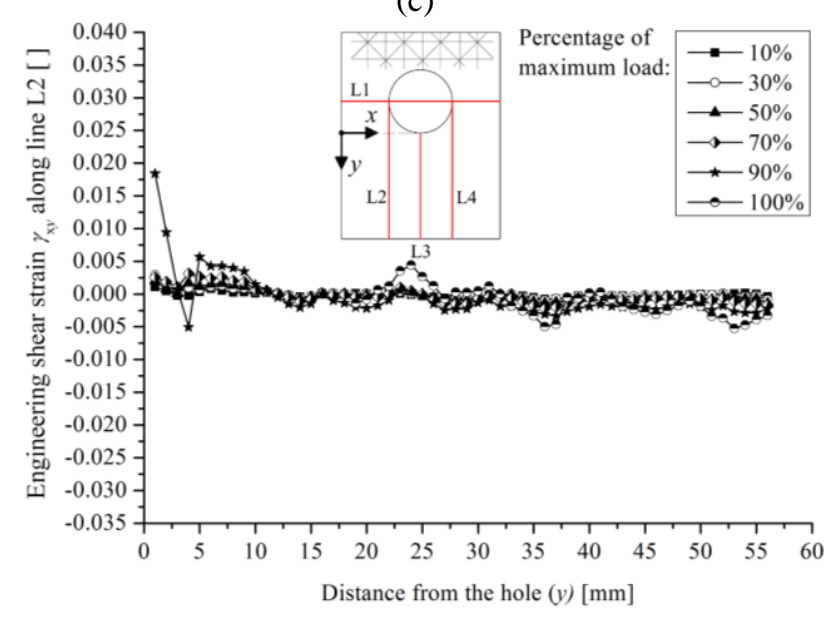

(d)

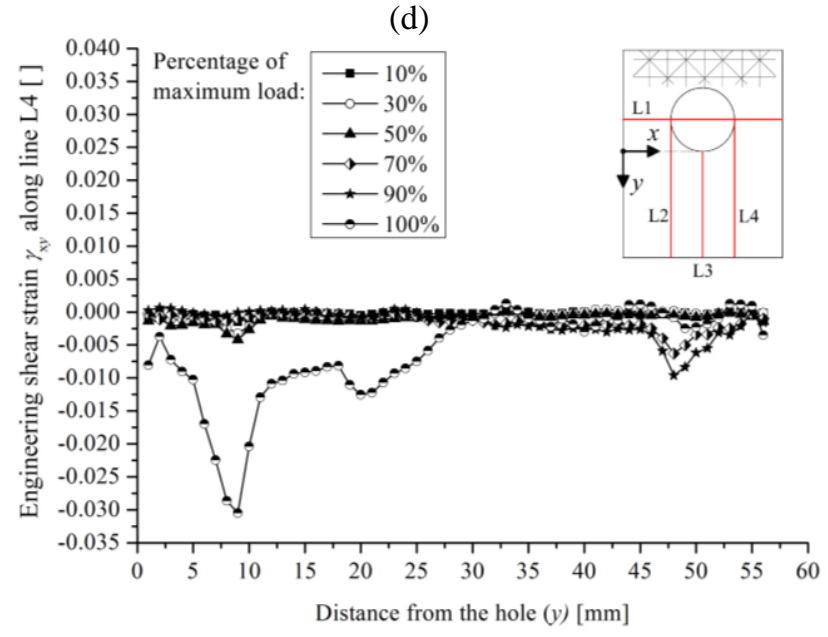

(e)

(f)

Figure 21: Engineering strain evolving along representative lines for a LAT/MU2 specimen: (a) $\varepsilon_{y}$ along line L1; (b) $\varepsilon_{x}$ along line L3; (c) $\varepsilon_{y}$ along line L3; (d) $\gamma_{x y}$ along line L3; (e) $\gamma_{x y}$ along line L2; (f) $\gamma_{x y}$ along line L4. Normal compression strain is positive. Shear strain is positive if it represents a decrease on the angle between the sides of an element of material lying parallel to the positive $x$ and $y$ axes.

On the other hand, the engineering strain diagrams along the representative lines of LAT specimens, presented in Figure 20Figure 20 and Figure 21Figure 21, show that the tensile normal strain $\varepsilon_{y}$ level attained in the BEL 
specimens was not achieved in LAT specimens, but similar strain distribution patterns were found, as these values increase towards the proximity with the holes in all tested specimens. However, a high compressive strain at $y$-direction in the vicinity of the hole was observed for both LAT specimens along line L3 (see Figure 20Figure 20c and d). In fact, the existence of this strain concentration just below the hole explains the bearing failure in the LAT specimens.

\section{PROPOSAL OF AN ANALYTICAL MODEL FOR PREDICTING LOAD CAPACITY OF PERFOFRP-CONCRETE CONNECTIONS UNDER TRANSVERSAL LOADS}

In this section an analytical framework to predict the ultimate load capacity of connections consisting on PERFOFRP connectors and concrete is described. In order to be able to undertake the validation of the proposed model and for the sake of simplicity, it was limited to the same laminates employed in the pull-out tests presented in the first part of this paper, that are: CSM and MU4 laminates.

As noticed in the performed experimental program [3], one particularity of connections consisting of PERFOFRP connectors and concrete is the fact that, when loaded transversally (under pull-out loads), the failure of the connection can be conditioned by the rupture of the connector itself. Thus, the formulation herein proposed to evaluate the load capacity of this type of connection needs to take into account both the possibility of rupture of GFRP connector and of concrete, as shown in Eq. (4(4).

$$
Q_{t r . u}^{p r}=\min \left\{\begin{array}{l}
Q_{t r . u . p}^{p r} \\
Q_{t r . u . c}^{\text {pr }}
\end{array}\right.
$$

where $Q_{t r . u . p}^{p r}$ is the predicted ultimate transversal load conditioned by the rupture of the GFRP connector and $Q_{t r . u . c}^{p r}$ is the predicted ultimate transversal load conditioned by the rupture of the concrete.

\subsection{Evaluation of the load capacity of the connections conditioned by the rupture of the GFRP connector}

Based on the experimental observations of pull-out tests presented in the first part of this paper [3] and on the experimental failure modes of the pin-bearing tests, the analytical framework made to predict the load capacity of PERFOFRP connections under transversal loads, $Q_{\text {tr.u.p }}^{p r}$, considers the possibility of occurring the four types of failure: net-tension $\left(Q_{t r . u . p . n t}^{p r}\right)$, shear-out $\left(Q_{t r . u . p . s o}^{p r}\right)$, bearing $\left(Q_{t r . u . p . b e}^{p r}\right)$ or cleavage $\left(Q_{t r . u . p . c l}^{p r}\right)$. In the proposed model, the load capacity of connection conditioned by the GFRP laminate is the minimum value among these values, as written in Eq. (5 $(5)$. 


$$
Q_{t r . u . p}^{\text {pr }}=\min \left\{\begin{array}{l}
Q_{t r . u . p . n t}^{\text {pr }} \\
Q_{t r . u . p . s o}^{\text {pr }} \\
Q_{\text {tr.u.p.be }}^{\text {pr }} \\
Q_{\text {tr.u.p.cl }}^{\text {pr }}
\end{array}\right.
$$

\subsubsection{Net-tension failure}

The maximum stress that can be introduced in net section $\left(\sigma_{n t \cdot \max }\right)$ is determined from Eq. (6) $(6)$, considering the following assumptions: the cumulative effect of multiple aligned holes is disregarded; Eq. (1)(1) is used to obtain the stress introduced in net section between the holes; the strain/stress concentration observed in the pin bearing tests is taken into account (see Figure 18Figure 18a, Figure 19Figure 19a, Figure 20Figure 20a and Figure 21Figure $21 \mathrm{a})$

$$
\sigma_{n t \max }=K_{I} \cdot \frac{Q_{t r}}{\left(W-D_{h}\right) \cdot t_{p}}
$$

where $Q_{t r}$ is the applied load, $W$ is the gross width of the laminate with one hole, $D_{h}$ is the diameter of the hole, and $t_{p}$ is the thickness of the laminate. $K_{I}$ is the stress intensity factor under mode I fracture. $K_{I}$ depends on the $W / D_{h}$ ratio and of type of laminate (i.e.; the stacking sequence and total content of fibres per direction) [34].

In the proposed model, it is considered that the failure mechanism in the connector takes place when $\sigma_{n t \text { max }}$ reaches the direct tensile strength of the composite in the load direction. Then, replacing $\sigma_{n t \text { max }}$ by the tensile strength of composite, $\sigma_{p t . u}$, and considering that the ultimate load of connector is related to the total number of holes, $n_{h}$, the load capacity of connector was predicted with the Eq. (7)(7).

$$
Q_{t r . u . p . n t}^{p r}=\frac{\sigma_{p t . u}\left(W-n_{h} \cdot D_{h}\right) t_{p}}{K_{I}}
$$

$K_{I}$ can be computed from Eq. (6)(6) using the data obtained in bearing tests with LAT/CSM and LAT/MU4 specimens. In fact, in the bearing tests with single hole specimens consisting of CSM and MU4 laminates, a mix of bearing and net-tension failure was attained. (i.e.; see results from Table 1 Table 1 and failure modes of Figure 9Figure 9). In the bearing tests with LAT specimens average failure loads equal to $9.74 \mathrm{kN}$ and $26.93 \mathrm{kN}$ were obtained for CSM and MU4 laminates, respectively. $K_{I}$ equal to 2.33 and 1.23 were obtained replacing these values in Eq. (7(7), considering $n_{h}$ equal to $1.0, W$ equal to the width of LAT specimens $(75 \mathrm{~mm})$, and $\sigma_{p t . u}$ equal to the tensile strength of CSM and MU4 laminates in the load direction (252.54 MPa and $183.48 \mathrm{MPa}$, respectively). In the LAT specimens used for bearing tests the distance between the hole and the lateral edge of laminate was 
representative of a $3 \mathrm{H}$ connector. For the sake of simplicity and due the lack of data to estimate the effect of $D_{h} / W$ ratio, $K_{I}$ was considered constant independently of the distance between holes. This is a reasonable simplification, taking into account that the distance between holes is going to be always around the values representative for $3 \mathrm{H}$ and $4 \mathrm{H}$ connectors used in this research.

\subsubsection{Shear-out:}

The shear out stresses were computed considering Eq. $\underline{(2)}(2)$. In this case, no stress concentration factors were considered because the shear strains along the lines that is supposed to obtain the maximum shear out stresses were almost uniform (see Figure 18Figure 18, Figure 19Figure 19, Figure 20Figure 20 and Figure 21Figure 21 e and f).

In the proposed model, it is considered that if the shear stress $\tau_{s o}$ reaches the shear strength of composite, shear-out failure occurs. Thus, the ultimate load of connector conditioned by the shear-out failure can be obtained replacing the shear-out stress by the shear strength of laminate and taking into account the number of holes of connector, $n_{h}$ (see Eq. $(8(8))$.

$$
Q_{\text {tr.u.p.so }}^{\text {pr }}=2 \cdot \tau_{x y . u} \cdot n_{h} \cdot e \cdot t_{p}
$$

where $\tau_{x y . u}$ is the shear strength of the laminate corresponding to the direction where the $x$-axis of material is perpendicular to the fracture line (see Figure 3Figure 3). This value was obtained only for the CSM laminate ( $\left.\tau_{x y . u}=139.06 \mathrm{MPa}\right)$, reason for the absence of estimations for the load capacity of connectors with MU4 conditioned by the shear out failure of connectors in this work.

\subsubsection{Bearing:}

As done in Eq. (3) (3), the variation of compressive stress along the perimeter contact between the pin and the hole was disregarded in the proposed model, and the applied load was assumed acting uniformly on the perimeter of the bottom semi-circumference of the hole (see Figure 3Figure 3c). Thus, the ultimate load of connector conditioned by bearing was obtained replacing the stress by the compressive strength of CSM and MU4 laminates. Taking into account that the load transferred for each hole is $Q / n_{h}$, where $n_{h}$ is the number of holes of connector, the predicted as given in Eq. $(9(9)$.

$$
Q_{\text {tr.u.p.be }}^{p r}=\sigma_{p c . u} \cdot n_{h} \cdot D_{h} \cdot t_{p}
$$

where $\sigma_{p c . u}$ is the compressive strength of the laminate corresponding to the load direction $\left(0^{\circ} / 90^{\circ}\right)$. The compressive strength of laminates used in this research work was not directly characterized Nonetheless, in the bearing tests with LAT specimens the CSM and MU4 laminates presented a combined rupture mode, failing at 
similar load levels by net-tension and bearing failure. In this manner, the compressive strengths of CSM and MU4 laminates were estimated using Eq. $(9(9)$ and the data obtained from bearing tests with CSM-LAT and MU4-LAT specimens for $n_{h}$ equal to 1.0. Considering that the average load capacities of CSM-LAT and MU4-LAT specimens were equal to $9.74 \mathrm{kN}$ and $26.93 \mathrm{kN}$ (see Table 1Table 1), values equal to $162.33 \mathrm{MPa}$ and $224.42 \mathrm{MPa}$ were obtained for $\sigma_{p c . u}$ of CSM and MU4 laminates, respectively.

\subsubsection{Cleavage}

To estimate the maximum load capable to be applied to the system prior the failure by cleavage, it was considered that the load applied to the connection $(Q)$ is equally distributed among the holes $\left(Q / n_{h}\right)$ and the load transferred to each hole is constant and uniformly distributed along the lower half of the hole $\left(p_{h}\right)$, as shown in Figure 22Figure 22. Thus, the distributed load in each hole $\left(p_{h}\right)$ was obtained dividing the total load applied to the connector by the number of holes and by the arch length that is distributed, as given in Eq. (10(10).

$$
p_{h}=\frac{2 \cdot Q}{n_{h} \cdot \pi \cdot D_{h}}
$$

The internal forces and the engineering stresses along the $x$-direction in the section immediately below the hole (section $s$ shown in Figure 22Figure 22) were estimated by modelling the hole as a simply clamped arch with rectangular section with height equal to $\left(e-D_{h} / 2\right)$ and width equal to $t_{p}$, as shown in Figure 22Figure 22. In such a way, the maximum axial stresses in the crown of the clamped arch were computed using the formulae proposed by Dym and Williams [35].

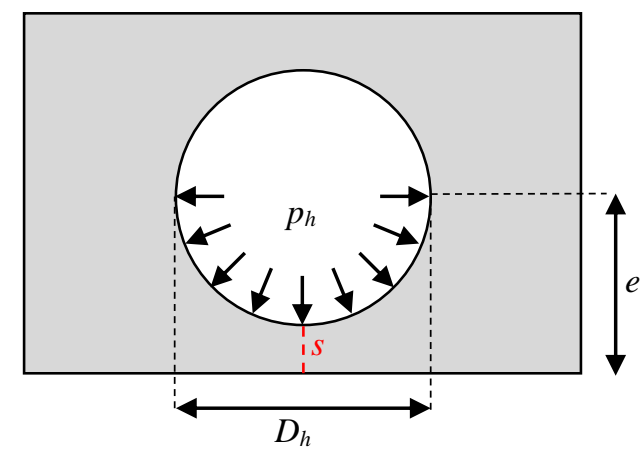

(a)
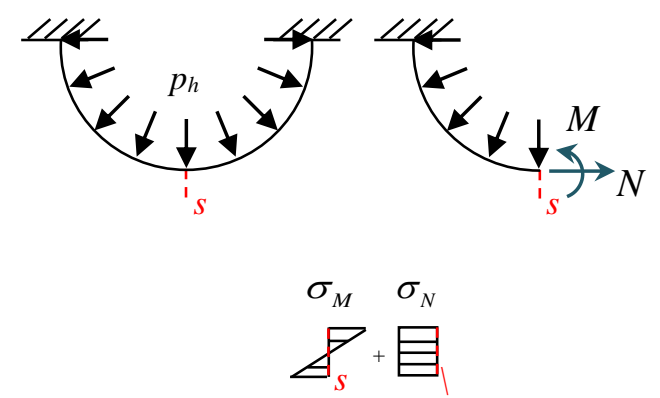

(b)

Figure 22: Model used to calculate the maximum axial stresses in the section $s$ : (a) load uniformly distributed in the lower bound of the connector; (b) clamped arch used to compute the internal forces and axial stresses. 
To take into account the uncertainties related to the problem (i.e.; distribution of the load transferred from the concrete dowel to the connector, anisotropy of the MU4 laminate, among others), a correction factor $\psi$ was introduced in the stress equation. The maximum normal tensile stress in the $x$-direction, developed in the section $s$ was calculated by the Eq. $(11)(11)$.

$$
\sigma_{x, \max }=\psi \cdot \frac{\pi^{2} \cdot D_{h}^{2} \cdot p_{h} \cdot\left(30 \cdot t_{p}+\pi^{2} \cdot D_{h}\right)}{2 \cdot t_{p} \cdot\left(e-\frac{D_{h}}{2}\right) \cdot\left(240 \cdot t_{p}{ }^{2}+\pi^{4} \cdot D_{h}{ }^{2}\right)}
$$

Replacing the equation Eq. (10) $(10)$ in Eq. (11) $(11)$, the maximum normal stress can be given by the Eq. $\underline{(12)}(12)$

$$
\sigma_{x . \max }=\psi \cdot \frac{\pi \cdot D_{h} \cdot Q \cdot\left(30 \cdot t_{p}+\pi^{2} \cdot D_{h}\right)}{n_{h} \cdot t_{p} \cdot\left(e-\frac{D_{h}}{2}\right) \cdot\left(240 \cdot t_{p}{ }^{2}+\pi^{4} \cdot D_{h}{ }^{2}\right)}
$$

Considering that the rupture of the connection by cleavage happens when the ultimate tensile stress of the laminate in the $x$-direction, $\sigma_{p t . u}$, is attained in the section $s$, the load capacity of the connection conditioned by cleavage,

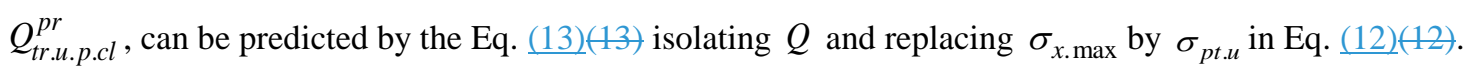

$$
Q_{t r . u . p . c l}^{p r}=\frac{\sigma_{p t . u} \cdot n_{h} \cdot t_{p} \cdot\left(e-\frac{D_{h}}{2}\right) \cdot\left(240 \cdot t_{p}{ }^{2}+\pi^{4} \cdot D_{h}^{2}\right)}{\psi \cdot \pi \cdot D_{h} \cdot\left(30 \cdot t_{p}+\pi^{2} \cdot D_{h}\right)}
$$

The values of the correction factor $\psi$ can be determined applying the Eq. $(13)(13)$ to the pin-bearing tests that failed by cleavage, that is, tests with BEL specimens (see Table 1Table 1 and Figure 8Figure 8 ). Using $n_{h}=1$ and adopting for $Q$ the ultimate load obtained in the bearing tests, $\psi$ values equal to 1.534 and 0.991 were obtained for CSM and MU4 laminates, respectively.

\subsection{Evaluation of the load capacity of the connections conditioned by the rupture of concrete}

As evidenced in the performed pull-out tests presented in the first part of this paper [3], when the rupture of concrete conditioned the load capacity of connections two main failure modes were evidenced: the concrete cone tensile fracture and the failure along the contact planes between the connector and concrete, i.e.; a combination of failure of concrete dowels and by friction/adhesion. Thus, the predicted load capacity of connection conditioned by the rupture of concrete, $Q_{t r . u . c}^{p r}$, can be obtained as the minimum value between the predicted rupture load by concrete cone fracture, $Q_{t r . u . c . c f}^{p r}$, and by shear along the contact line between the connector and the concrete, $Q_{t r . u . c . d f}^{p r}$, as given by Eq. (14)(14). 


$$
Q_{t r . u . c}^{p r}=\min \left\{\begin{array}{l}
Q_{t r . u . c . c f}^{p r} \\
Q_{\text {tr.u.c.df }}^{\text {pr. }}
\end{array}\right.
$$

\subsubsection{Concrete cone tensile fracture}

Concrete cone failure was observed for the studied connections consisting of SCC and SFRSCC, as shown in the first part of this paper [3]. This failure mode, named after the roughly cone shape of the piece of concrete witch pulls out in this kind of failure, hapens in the concrete block when principal tensile stresses transferred from the connector to the surrounding concrete reach its tensile strength and the concrete fractures along the surface that is the envelope of the compression isostatics. This is a failure mode commonly reported in pull-out tests with anchors, steel rebars and laminates embedded in concrete [36-38]. Several equations have been already proposed to predict the concrete breakout capacity [37, 39-42]. In general, predictions are made utilizing an idealized failure cone characterized by an effective height, $h_{e}$ and considering a uniform tensile stress distribution in the concrete at failure (see Figure 23Figure 23). In general, the existing equations compute the cone load capacity as the resultant of tensile stresses equal to maximum concrete tensile strength, $f_{c t}$, directed parallel to the applied load and acting on the projected area of the failure cone, $A_{p r .0}$. Considering that the cone angle is $\theta$ (see Figure 23Figure 23), the projected area can be estimated by $\frac{\pi}{2} \cdot\left(\frac{h_{e}}{\tan \theta}\right)^{2}$.

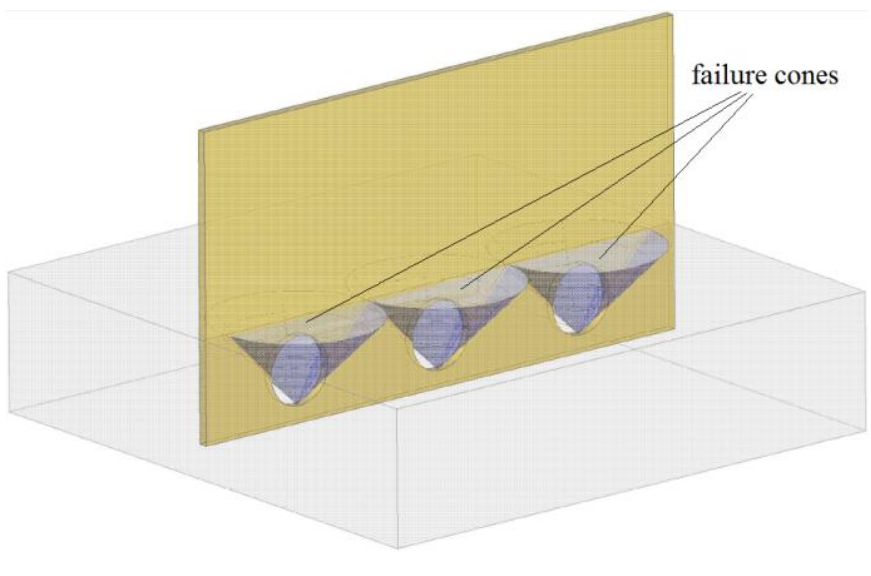

(a)

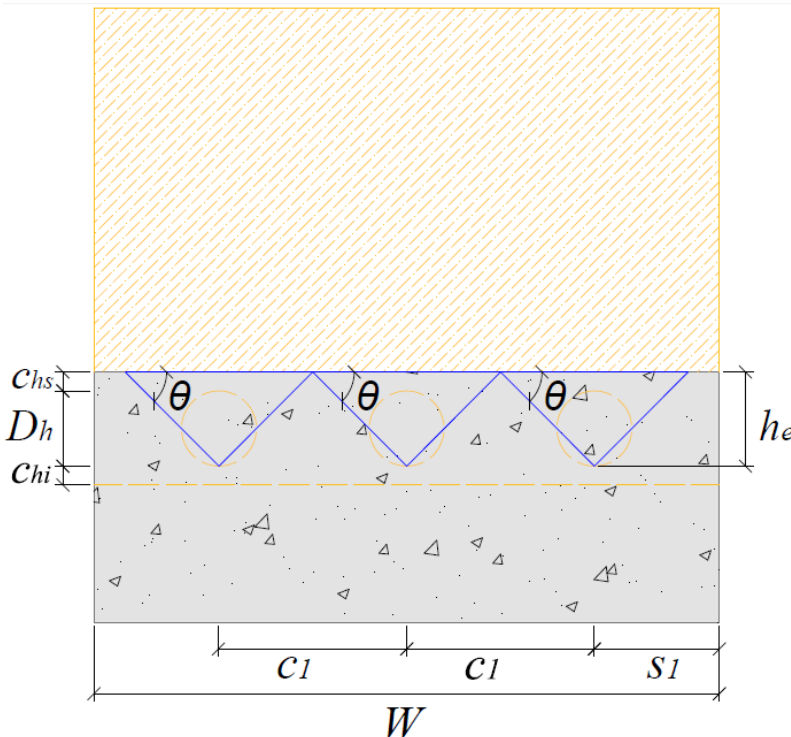

(b)

Figure 23: Schematic representation of concrete cone failure: (a) perspective; (b) cross-section. 
Although primarily developed for headed anchors, the formulae proposed by ACI Committee 349 [40] were adapted to estimate the load capacity of connections made with PERFOFRP connectors. As done by ACI Committee 349, a cone angle of $45^{\circ}$ was considered. Based on the experimental observation, the apex of the cone failure was considered to be in the lower edge of the concrete dowels, aligned with the middle of hole and with the thickness of the connector, as shown in Figure 23Figure 23. Thus, the load capacity of connector could be estimated by the Eq.

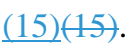

$$
Q_{t r . u . c f}^{p r}=f_{c t} \cdot A_{p r}
$$

where $f_{c t}$ is the tensile strength of concrete and $A_{p r}$ is the sum of the projected area of individual cones in a surface normal to the load direction, minus the areas of overlap and areas cut off by intersecting edges (see Figure 24Figure 24).The total projected area, $A_{p r .0}$, corresponding to all the cone failures, one for each of the $n_{h}$ holes of connector, was computed from Eq. (16)(16).

$$
A_{p r .0}=n_{h} \cdot \frac{\pi}{2} \cdot\left(\frac{h_{e}}{\tan \theta}\right)^{2}
$$
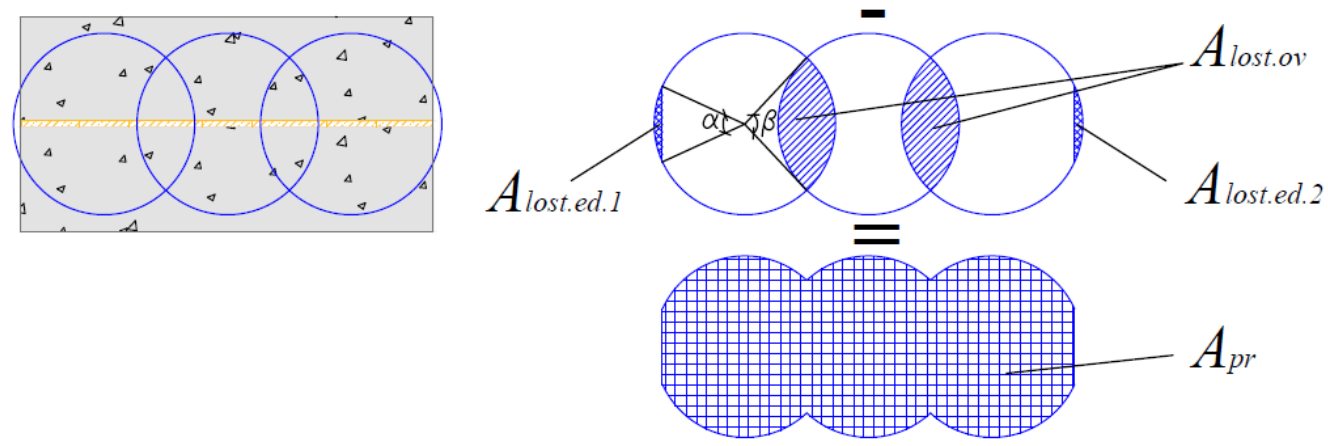

Figure 24: Determination of projected areas (plan view).

If the hole was located near a free edge, the projected area of the stress cone was reduced if the cone intersects the edge of the concrete (see Figure 24Figure 24). The edge problem resulted if $c_{1} /\left(h_{e} / \tan \theta\right)<1$. The amount to be reduced can be found by calculating the areas lost due to the proximity of all the edges $i, A_{\text {lost.ed.i }}$, using the Eq.(17)(17).

$$
A_{\text {lost.ed.i }}=\pi \cdot\left(\frac{h_{e}}{\tan \theta}\right)^{2} \cdot \frac{\beta}{360^{\circ}}-c_{1} \cdot \frac{h_{e}}{\tan \theta} \cdot \sin \left(\frac{\beta}{2}\right)
$$


where $\beta$ was the angle represented in Figure 24Figure 24, given in degrees, and can be computed by Eq.(18)(18).

$$
\beta=\cos ^{-1}\left[2 \cdot\left(c_{1} \cdot \frac{\tan \theta}{h_{e}}\right)^{2}-1\right]
$$

The total projected area was also reduced in the presence of multiple closely spaced cones if their failure surfaces overlapped. Considering an evenly distribution of holes spaced by $s_{1}$ (see Figure 24Figure 24), the overlap problem resulted if $s_{1} /\left(2 \cdot h_{e} / \tan \theta\right)<1$. Thus, the total overlapped area can be computed by Eq.(19)(19).

$$
A_{\text {lost.ov }}=\left(n_{h}-1\right) \cdot\left(\frac{h_{e}}{\tan \theta}\right)^{2} \cdot(\alpha-\sin \alpha)
$$

where $\alpha$ was the angle represented in Figure 24Figure 24, given in degrees, and was computed by Eq.(20)(20).

$$
\alpha=\cos ^{-1}\left[2 \cdot\left(\frac{s_{1}}{\frac{2 \cdot h_{e}}{\tan \theta}}\right)^{2}-1\right]
$$

Finally, the net projected area was equal to the difference between the projected area corresponding to a hole, not limited by edge influences $\left(A_{p r, 0}\right)$, and the sum of the areas of segments formed by the $n$ edges of the concrete acting as secant, as given by Eq.(21)(21).

$$
A_{p r}=A_{\text {pr. } 0}-A_{\text {lost.ov }}-\sum_{i=1}^{n} A_{\text {lost.ed. } i}
$$

The concrete average tensile strength, $f_{c t}$, was estimated from the compressive strength of SCC and SFRSCC by means of the formulae present in the fib Model Code 2010 [43], shown in Eq.(22)(22), resulting in $4.41 \mathrm{MPa}$ and 4.33 MPa for the SCC and SFRSCC, respectively. The contribution of steel fibres to the tensile strength of the SFRSCC was disregarded because the fibres volume fraction commonly used in steel fibre reinforced concretes are not sufficiently high to lead to increases on the tensile strength of the cementitious composite [44].

$$
f_{c t}=\left\{\begin{array}{c}
0.3 \cdot f_{c k}^{2 / 3} \quad \text { if } f_{c k} \leq 50 M P a \\
2.12 \cdot \ln \left(1+0.1 \cdot\left(f_{c k}+8 M P a\right)\right) \text { if } f_{c k}>50 M P a
\end{array}\right.
$$

Attention should be paid to the fact that, in the proposed model, the effect of adjacent holes on the failure of the GFRP plates is eliminated, while the effect of adjacent cones on SFRSCC failure is considered. The reason for this decision is the fact that a model that takes into account the effect of the adjacent holes on the failure of the GFRP plates would be much more complex than the proposed model. For a comprehensive consideration of this effect, it would be necessary to account for the anisotropic properties of GFRP and variables like the size and direction of glass fibres, for example. Note that the type of GFRP (mainly the direction of fibres) influences significantly the 
type of failure mode (i.e., geometry of failure). For the sake of simplicity, this effect was disregarded. On the other hand, it is much more reasonable to consider the SFRSCC as an isotropic material and that the failure mode and geometry of the concrete failure cone are not affected by the concrete properties.

\subsubsection{Shear along the contact line between the connector and the concrete (Shear in the Concrete Dowels plus Friction/Adhesion)}

Two different mechanisms are associated to the failure by shear along the contact area of connector and concrete: shear in the concrete dowels and friction/adhesion between the concrete and the two connector's contact surfaces.

The shear along the concrete dowels can be computed considering two hypotheses: (1) simple shear; (2) double shear occurs in the dowels. In the experimental study, after the pull-out tests it was evidenced in some cases that a slice of concrete remained in the hole of MU4 connectors, what could indicate that double shear is present when MU4 laminates, thicker than CSM laminate, is adopted.

The ultimate shear stress of concretes, $v_{c}$, were estimated using the empirical shear transfer model developed by Khanlou et al. [45], presented in Eq.(23)(23). This prediction model is based on regression analysis of data obtained from direct shear tests with hooked-end steel fibre reinforced concretes.

$$
v_{c}=0.75 \cdot \sqrt{f_{c k}}+4 \cdot V_{f}^{0.9}
$$

where $v_{c}$ and $f_{c k}$ are in $\mathrm{MPa}$ and $V_{f}$ is the volume fraction of steel fibres, expressed as a percentage. Using $f_{c k}=61.88 \mathrm{MPa}$ and $V_{f}=0.774 \%$ (i.e.; $60 \mathrm{~kg} / \mathrm{m}^{3}$ ), the ultimate shear stress of SFRSCC was estimated in $9.08 \mathrm{MPa}$. In the absence of fibres Eq. $(23)(23)$ reduces to $v_{c}=0.75 \cdot \sqrt{f_{c k}}$, which is the shear strength of plain concrete. This equation was used to compute the ultimate shear stress of SCC (found 5.9 MPa using $f_{c k}=59.12 \mathrm{MPa}$ ).

The friction/adhesion contribution was estimated from the experimental data obtained in the pull-out tests for $0 \mathrm{H}$ specimens, where only the friction/adhesion is present. A uniform stress distribution was considered, the friction/adhesion stress, that is related to the GFRP and concrete types, was computed dividing the peak load to the area of contact between the materials, considering the occurrence of double shear. Thus, considering the average peak load obtained in the pull-out tests and the contact area, friction/adhesion strengths, $\tau_{f r}$, equal to $0.83 \mathrm{MPa}$, 0.65 MPa, 0.99 MPa and 0.90 MPa were obtained for connections: CSM-SCC, CSM-SFRSCC, MU4-SCC and MU4-SFRSCC, respectively. Thus, the parcel of the load corresponding to the friction/adhesion is obtained multiplying $\tau_{f r}$ to the net contact area between the connector and the concrete. Differently from the equation of Sara and Bahram [46], the second term of Eq. (24)(24) considers the net contact area between the concrete and the connector. 
Therefore, joining both effects: shear in the concrete dowels and friction/adhesion, the load capacity conditioned by this failure mode was estimated by Eq. (24)(24), considering simple shear.

$$
Q_{u . t r . c . d f}^{p r}=\left[n_{h} \cdot\left(\frac{\pi \cdot D_{h}{ }^{2}}{4}\right)\right] \cdot v_{c}+2 \cdot\left[W \cdot\left(D_{h}+c_{h s}+c_{h i}\right)-n_{h} \cdot\left(\frac{\pi \cdot D_{h}{ }^{2}}{4}\right)\right] \cdot \tau_{f r}
$$

where $W \cdot\left(D_{h}+c_{h s}+c_{h i}\right)$ is the gross area corresponding to the region of connector that is embedded in the concrete, as shown in Figure 23Figure 23.

\subsection{Model validation}

In the Table 3 Table 3 the experimental and analytically predicted transversal load capacity of tested PERFOFRP connectors are compared. When the predicted load capacities of connections are compared to the values obtained experimentally, an average error of $19.57 \%$ was obtained.

The proposed model was able to predict very well the failure modes associated to the use of the different types of PERFOFRP connectors investigated. For instance, in the case of 3H-CSM-SCC and 3H-CSM-SFRSCC, a failure mode by cleavage of the CSM connector was predicted, which corresponds to what was experimentally evidenced. In average, the model underestimated the load capacity of 3H-CSM-SCC and 3H-CSM-SFRSCC connections on $1.05 \%$ and $16.36 \%$, respectively.

In the case of connections consisted of MU4 PERFOFRP, the predicted load capacity of connections were always conditioned by the rupture of the concrete. For 3H-MU4-SCC, the predicted failure mode was due to shear along the contact line between the connector and the concrete. In the other hand, for 3H-MU4-SFRSCC and 4H-MU4SFRSCC a concrete cone failure was predicted. Nonetheless, attention should be paid to the fact that, for the MU4 PERFOFRP connectors, the values of $Q_{t r . u . c f}^{p r}$ and $Q_{t r . u . d f}^{p r}$ were always quite similar. In fact, as reported in the first part of this companion paper [3], it was experimentally observed that these connections presented both types of rupture.

\section{Conclusions}

In this study, an in depth investigation was conducted on the mechanical behaviour of connections between concrete and PERFOFRP connectors when subjected to transversal loads. For a better understanding of the failure modes possible to occur by the rupture of the GFRP connector itself, an experimental investigation with 29 pin bearing tests was carried out with single hole plates made with different types of laminates. Based on the observed experimental behaviour of connections presented in the first part of this paper, and on the results of the pin-bearing tests, an empirical model was proposed to predict the ultimate load capacities of the studied connections. 
The results of pin-bearing tests indicated that, for the geometries and materials used in this investigation, when subjected to pull-out forces, the load capacity of the connectors is limited by the distance between the hole and the bottom edge of specimen, independently of the composite used. Furthermore, the advantage of using BIA and MU2 laminates instead of CSM laminate seems to be the more ductile rupture mode obtained when these materials are employed. In absence of the geometrical constrains encountered in this research that limits the distance between the hole edge and the below edge of connector, it is recommended to design the connector in order to avoid the rupture by cleavage. The experimental results obtained with LAT specimens indicate that, for all the materials studied and considering a connector with holes distanced $2.5 \mathrm{D}$ apart, when a ratio $e / D$ equal to 2.17 is adopted, the rupture tends to be more ductile. From observations during tests, this pseudo-ductile behaviour is associated to successive damages related to bearing failure mode.

The proposed empirical model considered that the load capacity of the connection can be limited by all the possible failure modes that can occur in the connector itself and also by the different failure modes associated to the rupture of concrete. The validity of the proposed formulae was checked and its capability to estimate the failure mode of the failure modes obtained in the pull-out experimental program was proved. When the predicted ultimate load capacities of connections were compared with the experimental results presented in the first part of this paper, an average error of $19.57 \%$ was obtained. Despite its good ability to predict experimental results, the model proposed in this paper should be used cautiously, since it was constructed based on an experimental results with a specific geometry (e.g., hole diameter and spacing between holes) and a limited number of materials (i.e., two types of GFRP and two types of concrete).

In further studies improvements should be implemented in the proposed model, namely in regard to considering the effect of the presence of multiple aligned holes in the connector or to explicit the effect of the properties of composites used in the connector. Also, the model shall be used to optimize the design of the connectors in terms of geometry and material properties in order to obtain a ductile failure mode at a certain required load level.

\section{ACKNOWLEDGEMENTS}

This work is part of the research project QREN number 5387, LEGOUSE, involving the companies Mota-Engil, CiviTest, the ISISE/University of Minho and PIEP. The first author would like to thank the financial support provided by PAIP/UNILA. The second author wish to acknowledge the grant SFRH/BSAB/114302/2016 provided by FCT. 
Table 3: Comparison between experimental and analytically predicted pull-out resistance of connections.

\begin{tabular}{|c|c|c|c|c|c|c|c|c|c|c|c|c|}
\hline \multirow[b]{2}{*}{ Specimen } & \multirow[b]{2}{*}{$\begin{array}{c}Q_{t r . u^{\exp }} \\
{[\mathrm{kN} / \mathrm{m}]}\end{array}$} & \multirow[b]{2}{*}{$\begin{array}{l}Q_{t r . u p . p h}{ }^{p r} \\
{[\mathrm{kN} / \mathrm{m}]}\end{array}$} & \multicolumn{4}{|c|}{ Conditioned by connector rupture } & \multicolumn{3}{|c|}{ Conditioned by concrete failure } & \multirow[b]{2}{*}{$\begin{array}{l}\text { Predicted } \\
\text { failure } \\
\text { mode** }\end{array}$} & \multirow[b]{2}{*}{$\begin{array}{c}Q_{t r r . u^{p r}} \\
{[\mathbf{k N} / \mathbf{m}]}\end{array}$} & \multirow[b]{2}{*}{$\begin{array}{c}\text { Error } \\
{[\%]}\end{array}$} \\
\hline & & & $\begin{array}{c}Q_{\text {tru.u.p.so }}^{p r} \\
{[\mathrm{kN} / \mathrm{m}]}\end{array}$ & $\begin{array}{l}Q_{t r . u p . b e}{ }^{p r} \\
{[\mathrm{kN} / \mathrm{m}]}\end{array}$ & $\begin{array}{l}Q_{\text {tr.u.p.c }}{ }^{p r} \\
{[\mathrm{kN} / \mathrm{m}]}\end{array}$ & $\begin{array}{c}Q_{\text {tr. } u . p}^{p r}{ }^{p r} \\
{[\mathbf{k N} / \mathbf{m}]}\end{array}$ & $\begin{array}{l}Q_{\text {tr.u.c. }} p^{p r} \\
{[\mathrm{kN} / \mathrm{m}]}\end{array}$ & $\begin{array}{l}Q_{\text {tr.u.c. }} f^{p r} \\
{[\mathrm{kN} / \mathrm{m}]}\end{array}$ & $\begin{array}{c}Q_{\text {tr.u. }}^{p r}{ }^{p r} \\
{[\mathbf{k N} / \mathbf{m}]}\end{array}$ & & & \\
\hline 3H-CSM-SCC 01 & 69.1 & 137.26 & 153.22 & 118.78 & 79.51 & 79.51 & 118.67 & 111.09 & 111.09 & p.cl & 79.51 & 15.1 \\
\hline 3H-CSM-SCC 02 & 91.6 & 137.26 & 153.22 & 118.78 & 79.51 & 79.51 & 118.67 & 111.09 & 111.09 & p.cl & 79.51 & -13.2 \\
\hline 3H-CSM-SFRSCC 01 & 94.8 & 137.26 & 153.22 & 118.78 & 79.51 & 79.51 & 116.66 & 125.21 & 116.66 & p.cl & 79.51 & -16.1 \\
\hline 3H-CSM-SFRSCC 02 & 89.9 & 137.26 & 153.22 & 118.78 & 79.51 & 79.51 & 116.66 & 125.21 & 116.66 & p.cl & 79.51 & -11.6 \\
\hline 3H-CSM-SFRSCC 03 & 100.5 & 137.26 & 153.22 & 118.78 & 79.51 & 79.51 & 116.66 & 125.21 & 116.66 & p.cl & 79.51 & -20.9 \\
\hline 3H-MU4-SCC 01 & 93.16 & 379.50 & * & 328.41 & 158.05 & 158.05 & 129.65 & 122.65 & 122.65 & c.df & 122.65 & 31.7 \\
\hline 3H-MU4-SCC 02 & 100.3 & 379.50 & $*$ & 328.41 & 158.05 & 158.05 & 129.65 & 122.65 & 122.65 & c.df & 122.65 & 22.3 \\
\hline 3H-MU4-SCC 03 & 86.75 & 379.50 & $*$ & 328.41 & 158.05 & 158.05 & 129.65 & 122.65 & 122.65 & c.df & 122.65 & 41.4 \\
\hline 3H-MU4-SFRSCC 01 & 103.72 & 379.50 & $*$ & 328.41 & 158.05 & 158.05 & 127.45 & 143.65 & 127.45 & c.cf & 127.45 & 22.9 \\
\hline 3H-MU4-SFRSCC 02 & 117.48 & 379.50 & $*$ & 328.41 & 158.05 & 158.05 & 127.45 & 143.65 & 127.45 & c.cf & 127.45 & 8.5 \\
\hline 3H-MU4-SFRSCC 03 & 103.37 & 379.50 & $*$ & 328.41 & 158.05 & 158.05 & 127.45 & 143.65 & 127.45 & c.cf & 127.45 & 23.3 \\
\hline 4H-MU4-SFRSCC 01 & 110.45 & 306.52 & $*$ & 437.89 & 210.73 & 210.73 & 127.45 & 164.56 & 127.45 & c.cf & 127.45 & 15.4 \\
\hline 4H-MU4-SFRSCC 03 & 113.76 & 306.52 & $*$ & 437.89 & 210.73 & 210.73 & 127.45 & 164.56 & 127.45 & c.cf & $\mathbf{1 2 7 . 4 5}$ & 12.0 \\
\hline
\end{tabular}

*- not enough data to predict the $\tau_{\text {xy.u }}$ of MU4 laminate.

**- p.cl: connector failure by cleavage; c.df: concrete failure by shear in the dowels plus friction/adhesion; c.cf: concrete cone failure. 


\section{LIST OF TABLES}

Table 1: Failure mode and ultimate load for each specimen.

Table 2: Strain attained in the gross section of specimen.

Table 3: Comparison between experimental and analytically predicted pull-out resistance of connections.

*- corresponding author. 


\section{LIST OF FIGURES}

Figure 1: GFRP connector for concrete structural panels: (a) overall view of connectors during the casting of concrete top layer of a sandwich panel; (b) detail of one PERFOFRP connector.

Figure 2: Common failure modes described in the literature: (a) net-tension; (b) shear-out; (c) bearing; (d) cleavage. Figure 3: Schematic representation of the stresses computed for: (a) net-tension; (b) shear-out; (c) bearing.

Figure 4: Type of specimens: (a) BEL; (b) LAT (dimensions in millimetres).

Figure 5: Schematic representation of test-setups adopted for the pin-bearing tests: (a) original test setup (SIM): front view; (b) SIM: lateral view; (c) modified test setup (CAN): front view; (d) CAN: lateral view.

Figure 6: Instrumentation adopted: (a) clip-on gauge in the middle section of specimen; (b) schematic representation of three configurations adopted to measure the deformation in the proximity of hole; (c) detail of the ESG glued immediately below the hole of BEL specimen; (c) detail of ESG glued next to the hole of LAT / MU4 specimen.

Figure 7: Typical mixed failure sequence for: (a) BEL specimens; (b) LAT specimens.

Figure 8: Final appearance of BEL specimens.

Figure 9: Final appearance of LAT specimens.

Figure 10: Load versus displacement curves for the BEL specimens: (a) CSM; (b) BIA; (c) MU2; (d) MU4.

Figure 11: Load versus displacement curves for the LAT specimens: (a) CSM; (b) BIA; (c) MU2; (d) MU4.

Figure 12: Shear-out stress vs. engineering strain $\varepsilon_{\mathrm{x}}$ in the proximity of hole corresponding to BEL specimens. Laminates: (a) CSM; (b) BIA; (c) MU2; (d) MU4.

Figure 13: Bearing stress vs. engineering strain in the proximity of hole corresponding to LAT specimens: (a) CSM; (b) BIA; (c) MU2; (d) MU4 - front and back; (e) MU4 - left and right; (f) MU4 - below.

Figure 14: Engineering strain field evolving along the test for a BEL/CSM specimen. (a) $\varepsilon_{x}\left(50 \%\right.$ of $F_{\max }$ ); (b) $\varepsilon_{x}$ (75\% of $\left.F_{\max }\right) ;(\mathrm{c}) \varepsilon_{x}\left(100 \%\right.$ of $\left.F_{\max }\right) ;(\mathrm{d}) \varepsilon_{y}\left(50 \%\right.$ of $\left.F_{\max }\right) ;(\mathrm{e}) \varepsilon_{y}\left(75 \%\right.$ of $\left.F_{\max }\right) ;(\mathrm{f}) \varepsilon_{y}\left(100 \%\right.$ of $F_{\max }$. Units: []. Normal compression strain is positive.

Figure 15: Engineering strain field evolving along the test for a BEL/MU2 specimen. (a) $\varepsilon_{x}\left(50 \%\right.$ of $F_{\max }$ ); (b) $\varepsilon_{x}$ (75\% of $\left.F_{\max }\right)$; (c) $\varepsilon_{x}\left(100 \%\right.$ of $\left.F_{\max }\right) ;(\mathrm{d}) \varepsilon_{y}\left(50 \%\right.$ of $\left.F_{\max }\right) ;(\mathrm{e}) \varepsilon_{y}\left(75 \%\right.$ of $\left.F_{\max }\right) ;(\mathrm{f}) \varepsilon_{y}\left(100 \%\right.$ of $\left.F_{\max }\right)$. Units: [ ]. Normal compression strain is positive.

Figure 16: Engineering strain field evolving along the test for a LAT/CSM specimen. (a) $\varepsilon_{x}\left(50 \%\right.$ of $\left.F_{\max }\right)$; (b) $\varepsilon_{x}$ $\left(75 \%\right.$ of $\left.F_{\max }\right) ;(\mathrm{c}) \varepsilon_{x}\left(100 \%\right.$ of $\left.F_{\max }\right) ;(\mathrm{d}) \varepsilon_{y}\left(50 \%\right.$ of $\left.F_{\max }\right) ;(\mathrm{e}) \varepsilon_{y}\left(75 \%\right.$ of $\left.F_{\max }\right) ;(\mathrm{f}) \varepsilon_{y}\left(100 \%\right.$ of $F_{\max }$. Units: [ ]. Normal compression strain is positive. 
Figure 17: Engineering strain field evolving along the test for a LAT/MU2 specimen. (a) $\varepsilon_{x}\left(50 \%\right.$ of $F_{\max }$ ); (b) $\varepsilon_{x}$ $\left(75 \%\right.$ of $\left.F_{\max }\right) ;(\mathrm{c}) \varepsilon_{x}\left(100 \%\right.$ of $\left.F_{\max }\right) ;(\mathrm{d}) \varepsilon_{y}\left(50 \%\right.$ of $\left.F_{\max }\right) ;(\mathrm{e}) \varepsilon_{y}\left(75 \%\right.$ of $\left.F_{\max }\right) ;(\mathrm{f}) \varepsilon_{y}\left(100 \%\right.$ of $\left.F_{\max }\right)$. Units: [ ]. Normal compression strain is positive.

Figure 18: Engineering strain evolving along representative lines for a BEL/CSM specimen: (a) $\varepsilon_{y}$ along line L1; (b) $\varepsilon_{x}$ along line L3; (c) $\varepsilon_{y}$ along line L3; (d) $\gamma_{x y}$ along line L3; (e) $\gamma_{x y}$ along line L2; (f) $\gamma_{x y}$ along line L4. Normal compression strain is positive. Shear strain is positive if it represents a decrease on the angle between the sides of an element of material lying parallel to the positive $x$ and $y$ axes.

Figure 19: Engineering strain evolving along representative lines for a BEL/MU2 specimen: (a) $\varepsilon_{y}$ along line L1; (b) $\varepsilon_{x}$ along line L3; (c) $\varepsilon_{y}$ along line L3; (d) $\gamma_{x y}$ along line L3; (e) $\gamma_{x y}$ along line L2; (f) $\gamma_{x y}$ along line L4. Normal compression strain is positive. Shear strain is positive if it represents a decrease on the angle between the sides of an element of material lying parallel to the positive $x$ and $y$ axes.

Figure 20: Engineering strain evolving along representative lines for a LAT/CSM specimen: (a) $\varepsilon_{y}$ along line L1; (b) $\varepsilon_{x}$ along line L3; (c) $\varepsilon_{y}$ along line L3; (d) $\gamma_{x y}$ along line L3; (e) $\gamma_{x y}$ along line L2; (f) $\gamma_{x y}$ along line L4. Normal compression strain is positive. Shear strain is positive if it represents a decrease on the angle between the sides of an element of material lying parallel to the positive $x$ and $y$ axes.

Figure 21: Engineering strain evolving along representative lines for a LAT/MU2 specimen: (a) $\varepsilon_{y}$ along line L1; (b) $\varepsilon_{x}$ along line L3; (c) $\varepsilon_{y}$ along line L3; (d) $\gamma_{x y}$ along line L3; (e) $\gamma_{x y}$ along line L2; (f) $\gamma_{x y}$ along line L4. Normal compression strain is positive. Shear strain is positive if it represents a decrease on the angle between the sides of an element of material lying parallel to the positive $x$ and $y$ axes.

Figure 22: Model used to calculate the maximum axial stresses in the section $s$ : (a) load uniformly distributed in the lower bound of the connector; (b) clamped arch used to compute the internal forces and axial stresses.

Figure 23: Schematic representation of concrete cone failure: (a) perspective; (b) cross-section.

Figure 24: Determination of projected areas (plan view). 


\section{REFERENCES}

[1] R. Lameiras, J. Barros, M. Azenha, I.B. Valente, Development of sandwich panels combining fibre reinforced concrete layers and fibre reinforced polymer connectors. Part I: conception and pull-out tests, Composite Structures 105(November 2013) (2013) 446-459.

[2] R. Lameiras, J. Barros, M. Azenha, I.B. Valente, Development of sandwich panels combining fibre reinforced concrete layers and fibre reinforced polymer connectors. Part II: Evaluation of mechanical behaviour, Composite Structures 105(0) (2013) 460-470.

[3] R.M. Lameiras, I.B. Valente, J. Barros, M. Azenha, C. Gonçalves, Pull-out behaviour of glass-fibre reinforced polymer perforated plate connectors embedded in concrete. Part I: Experimental program, In this Journal In this Volume(In this Issue) (2015).

[4] T.A. Collings, The strength of bolted joints in multi-directional CFRP laminates, Composites 8(1) (1977) 43-55.

[5] R. Karakuzu, N. Taylak, B.M. İçten, M. Aktaş, Effects of geometric parameters on failure behavior in laminated composite plates with two parallel pin-loaded holes, Composite Structures 85(1) (2008) 1-9.

[6] CEN, EN 1992-1 European Standard Eurocode 2: Design of concrete structures - Part 1: general rules and rules for buildings., Brussels, 2004.

[7] F.-K. Chang, R.A. Scott, G.S. Springer, Failure of Composite Laminates Containing Pin Loaded Holes-Method of Solution, Journal of Composite Materials 18(3) (1984) 255-278.

[8] D. Liu, B.B. Raju, Thickness effects on pinned joints for composites, Journal of Composite Materials 33 (1999) 2-21.

[9] F. Pierron, F. Cerisier, M. Grediac, A Numerical and Experimental Study of Woven Composite Pin-Joints, Journal of Composite Materials 34(12) (2000) 1028-1054.

[10] B. Okutan, The effects of geometric parameters on the failure strength for pin-loaded multidirectional fiber-glass reinforced epoxy laminate, Composites Part B: Engineering 33(8) (2002) 567-578.

[11] ASTM, D5961 / D5961M - 13: Standard Test Method for Bearing Response of Polymer Matrix Composite Laminates, American Society for Testing and Materials (ASTM), Philadelphia, PA, 2013.

[12] G. Caprino, A. Squillace, G. Giorleo, L. Nele, L. Rossi, Pin and bolt bearing strength of fibreglass/aluminium laminates, Composites Part A: Applied Science and Manufacturing 36(9) (2005) 1307-1315.

[13] C.N. Rosner, S.H. Rizkalla, Bolted connections for fiber-reinforced composite material members: analytical model and design recommendations, Journal of Materials in Civil Engineering 7(4) (1995) 232-238.

[14] A. Valenza, V. Fiore, L. Calabrese, G. Di Bella, Failure map of composite laminate mechanical joint, Journal of Composite Materials 41(8) (2007).

[15] W.J. Slagter, On the bearing strength of fibre metal laminates, Journal of Composite Materials 26 (1992) 2542-2566.

[16] C. Cooper, G.J. Turvey, Effects of joint geometry and bolt torque on the structural performance of single bolt tension joints in pultruded GRP sheet material, Composite Structures 32(1-4) (1995) 217-226.

[17] T.J. Wu, H.T. Hahn, The bearing strength of e-glass/vynil-ester composites fabricated by vartm, Composite Science and Technology 5(8) (1998) 1519-1529.

[18] P.A. Smith, K.J. Pascoe, The effect of stacking sequence on the bearing strengths of quasiisotropic composite laminates, Composite Structures 6(1-3) (1986) 1-20.

[19] G.R. Pyner, F.L. Matthews, Comparison of Single and Muilti-Hole Bolted Joints in Glass Fibre Reinforced Plastic, Journal of Composite Materials 13 (1979) 232-239.

[20] E.W. Godwin, F.L. Matthews, A review of the strength of joints in fibre-reinforced plastics: Part 1. Mechanically fastened joints, Composites 11(3) (1980) 155-160. 
[21] G. Kretsis, F.L. Matthews, The strength of bolted joints in glass fibre/epoxy laminates, Composites 16(2) (1985) 92-102.

[22] R. Karakuzu, B.M.M. Icten, O. Tekinsen, Failure behavior of composite laminates with multi-pin loaded holes, Journal of Reinforced Plastics and Composites 29(2) (2010).

[23] E.C. Oguejiofor, M.U. Hosain, A parametric study of perfobond rib shear connectors, Canadian Journal of Civil Engineering 21(4) (1994) 614-625.

[24] E.C. Oguejiofor, M.U. Hosain, Numerical analysis of push-out specimens with perfobond rib connectors, Computers \& Structures 62(4) (1997) 617-624.

[25] A.M.R. Sousa, J. Xavier, M. Vaz, J.J.L. Morais, V.M.J. Filipe, Cross-correlation and differential technique combination to determine displacement fields, Strain 47(SUPPL.2) (2011) $87-98$.

[26] J. Xavier, A.M.P. de Jesus, J.J.L. Morais, J.M.T. Pinto, Stereovision measurements on evaluating the modulus of elasticity of wood by compression tests parallel to the grain, Construction and Building Materials 26(1) (2012) 207-215.

[27] J. Xavier, M. Oliveira, P. Monteiro, J.J.L. Morais, M.F.S.F. Moura, Direct Evaluation of Cohesive Law in Mode I of Pinus pinaster by Digital Image Correlation, Experimental Mechanics (2014) 1-12.

[28] A.M.R. Sousa, J. Xavier, M. Vaz, J.J.L. Morais, V.M.J. Filipe, Cross-Correlation and Differential Technique Combination to Determine Displacement Fields, Strain 47 (2011) 87-98.

[29] A.R. Bunsell, J. Renard, Fundamentals of fibre reinforced composite materials, IOP Publishing, Bristol, UK, 2005.

[30] L. Bank, Progressive Failure and Ductility of FRP Composites for Construction: Review, Journal of Composites for Construction 17(3) (2013) 406-419.

[31] L.C. Bank, D. Arora, Analysis of RC beams strengthened with mechanically fastened FRP (MF-FRP) strips, Composite Structures 79(2) (2007) 180-191.

[32] T. Yýlmaz, T. Sýnmazçelik, Investigation of load bearing performances of pin connected carbon/polyphenylene sulphide composites under static loading conditions, Materials \& Design 28(2) (2007) 520-527.

[33] R. Lameiras, J. Barros, I.B. Valente, M. Azenha, Development of sandwich panels combining fibre reinforced concrete layers and fibre reinforced polymer connectors. Part I: Conception and pull-out tests, Composite Structures 105(0) (2013) 446-459.

[34] L. Toubal, M. Karama, B. Lorrain, Stress concentration in a circular hole in composite plate, Composite Structures 68(1) (2005) 31-36.

[35] C.L. Dym, H.E. Williams, Stress and Displacement Estimates for Arches, Journal of Structural Engineering 137(1) (2011) 49-58.

[36] R. Eligehausen, T. Balogh, Behavior of fasteners loaded in tension in cracked reinforced concrete, ACI Structural Journal 92(3) (1995) 365-379.

[37] C.B. Farrow, I. Frigui, R.E. Klingner, Tensile capacity design of single anchors in concrete: Evaluation of existing formulas on an LRFD basis, ACI Structural Journal 93(128-137) (1996).

[38] R.E.K. Mansour Shirvani, L.G. Herman, III, Breakout Capacity of Anchors in Concrete Part 1: Tension, Structural Journal 101(6) (2004).

[39] R.E. Klingner, J.A. Mendonca, Tensile Capacity of Short Anchor Bolts and Welded Studs: A Literature Review, ACI JOURNAL 79(4) (1982) 270-279.

[40] ACI Committee 349, Code Requirements for Nuclear Safety Related Structures (ACI 34985) (Revised 1990) (Reapproved 1997), Technical Documents, Farmington Hills, Mich., 1985, p. 134.

[41] W. Fuchs, R. Eligehausen, J.E. Breen, Concrete Capacity Design (CCD) Approach for Fastening to Concrete, Structural Journal 92(1) (1995).

[42] J.-P.P. Eric J. Primavera, H.K. Edward, Tensile Behavior of Cast-in-Place and Undercut Anchors in High-Strength Concrete, Structural Journal 94(5) (1997). 
[43] Fédération Internationale du Béton (fib), fib Model Code for Concrete Structures 2010 (MC2010), fédération internationale du béton, Lausanne, Switzerland, 2012.

[44] A. Bentur, S. Mindess, Fibre reinforced cementitious composites, CRC Press2006.

[45] A. Khanlou, G.A. MacRae, A.N. Scott, S.J. Hicks, G.C. Clifton, Shear performance of steel fibre-reinforced concrete, Steel Innovations Conference 2013, Christchurch, New Zeland, 2013.

[46] B.M. Sara, M.S. Bahram, Perfobond shear connectors for composite construction, Engineering Journal (AISC - American Institute of Steel Construction) first quarter (2002) 2-12. 